\title{
Experimental and Simulation Analysis of Temperature and Particulate Matter Distribution for a Catalyzed Diesel Particulate Filter
}

\author{
Boopathi S. Mahadevan ${ }^{1}$ • John H. Johnson ${ }^{1} \cdot$ Mahdi Shahbakhti $^{1}$
}

Received: 9 April 2015 /Revised: 18 June 2015 / Accepted: 7 July 2015 / Published online: 15 August 2015

(C) Springer SIP, AG 2015

\begin{abstract}
A multi-zone particulate filter (MPF) model from reference [1] was extended to analyze temperature and particulate matter (PM) distribution within each axial and radial zone of the filter substrate. A parametric study was used to determine the optimum required number of zones in the MPF model in the range of $5 \times 5$ to $20 \times 20$ zones for aftertreatment control applications. The MPF model with $10 \times 10$ zones was optimum and ran 12.2 times faster than real time. The $10 \times 10$ zone MPF model was calibrated using eighteen runs of data from a 2007 Cummins ISL engine that consisted of passive and active regeneration data sets for ultra-low-sulfur diesel (ULSD), diesel blend (ULSD) with $10 \%$ biodiesel (B10), and diesel blend (ULSD) with $20 \%$ biodiesel (B20) fuels. The MPF model was accurate, with maximum root mean square (RMS) error of $2.1 \mathrm{~g}$ for predicting PM loading and RMS error of within $10{ }^{\circ} \mathrm{C}$ for predicting temperature distribution within the filter. The PM distribution trends simulated by the MPF model were in good agreement with the experimental data measured using a terahertz wave scanner. The study of PM distribution during loading and at the end of PM oxidation (passive oxidation and active regeneration) showed that the PM oxidation by active regeneration leads to greater non-uniform PM loading of the filter compared to the passive oxidation as quantified using the uniformity index (UI) which was developed in the research to quantify the PM and temperature distribution.
\end{abstract}

Boopathi S. Mahadevan

bsingala@mtu.edu

Michigan Technological University, 815 RL Smith Building, 1400 Townsend Drive, Houghton, MI 49931, USA
Keywords Diesel particulate filter model · ECU-based particulate filter model · Temperature distribution · Particulate loading distribution · Diesel exhaust emission control

$\begin{array}{ll}\text { Abbreviations } \\ \text { AR } & \text { Active regeneration } \\ \text { B10 } & \text { Diesel blend (ULSD) with } 10 \% \text { biodiesel } \\ \text { B20 } & \text { Diesel blend (ULSD) with } 20 \% \text { biodiesel } \\ \text { CFD } & \text { Computational fluid dynamics } \\ \text { CPF } & \text { Catalyzed particulate filter } \\ \text { CO }_{2} & \text { Carbon dioxide } \\ \text { DOC } & \text { Diesel oxidation catalyst } \\ \text { DPF } & \text { Diesel particulate filter } \\ \text { ECU } & \text { Electronic control unit } \\ \text { FESEM } & \text { Field emission scanning electron microscopy } \\ \text { GB } & \text { Gigabyte } \\ \text { LDA } & \text { Laser Doppler Anemometer } \\ \text { MPF } & \text { Multi-zone particulate filter } \\ \text { MTU } & \text { Michigan Technological University } \\ \text { NO } & \text { Nitrogen dioxide } \\ \text { NO } & \text { Nitrogen monoxide } \\ \text { O } 2 & \text { Oxygen } \\ \text { OBD } & \text { On-board diagnostics } \\ \text { PO } & \text { Passive oxidation } \\ \text { PM } & \text { Particulate matter } \\ \text { RAM } & \text { Random access memory } \\ \text { RMS } & \text { Root mean square } \\ \text { RU } & \text { Ramp up } \\ \text { SEM } & \text { Scanning electron microscopy } \\ \text { SCR } & \text { Selective catalytic reduction } \\ \text { UI } & \text { Uniformity index } \\ \text { ULSD } & \text { Ultra-low-sulfur diesel } \\ \text { 1-D } & \text { One-dimensional } \\ 3-D & \text { Three-dimensional } \\ & \end{array}$




\section{Introduction}

Catalyzed particulate filters (CPF) are widely used to meet current and future heavy-duty diesel emission regulations. The heavy-duty emission regulations also require on-board diagnostics (OBD) to monitor the performance of the emission control system during in-use vehicle operating conditions. An advanced model for potential use for controls such as one developed in reference [1] can monitor the performance of CPF (temperature and particulate matter (PM) distribution within the filter). The multi-zone particulate filter (MPF) model developed in reference [1] showed good capability to predict temperature and PM distribution within the filter and has the potential for control capability with further development. This work builds upon our previous MPF modeling study [1] and presents (i) new detailed model validation with extensive experimental data and (ii) detailed experimental and modeling analysis of the CPF.

The simulation of PM distribution trends of the multi-zone model intended for the electronic control unit (ECU) application is the key outcome of this research, and authors are not aware of any previous research work related to this work especially for a multi-zone CPF model for ECU applications. In this research, an extensive analysis and validation of ECUbased multi-zone model using the real engine experiments for wide range of passive oxidation and active regeneration test conditions were carried out. They include (i) comparison and analysis of experimental internal filter substrate temperatures with the simulation data; (ii) comparison and analysis of engine experimental PM distribution trends measured by the terahertz wave scanner with the PM mass distribution simulation data; (iii) validation of simultaneous PM loading and oxidation model results with the engine experimental data (PM mass retained); (iv) prediction and analysis of uniformity index for PM loading, substrate temperature, and reaction rates for both passive oxidation and active regenerations; and (v) a comprehensive assessment (discretization size, model run time, and accuracy) of MPF model capability to run in an engine ECU for predicting the temperature and PM loading distribution within the CPF. This real-time running capability of the MPF model will aid in regeneration control and monitoring the performance of $\mathrm{CPF}$ to meet OBD requirements which are the uniqueness of this research and such model validation and analysis with real engine data is not documented in any of the earlier research that the authors are aware of.

The overall objective of this research is to analyze the temperature and PM distribution of a CPF for ultra-low-sulfur diesel (ULSD), diesel blend (ULSD) with $10 \%$ biodiesel (B10), and diesel blend (ULSD) with $20 \%$ biodiesel (B20) fuels based on engine experimental data for passive oxidation and active regeneration conditions by extending the MPF model developed in reference [1].
To present the approach to fulfill the above objective, the paper is organized into seven components of research:

1. Review the literature related to multi-dimensional temperature and PM distribution modeling and experimental investigations.

2. Study the effect of the number of axial/radial zones on model run time and accuracy as related to the measured temperature data using the MPF model.

3. Analyze the PM kinetics and PM distribution of the CPF for ULSD, B10, and B20 fuels using the experimental data [2-5] for passive oxidation and active regeneration test conditions. Determine the model prediction accuracy related to PM mass retained and temperature distribution.

4. Analyze the PM distribution trends predicted by the MPF model during loading and at the end of PM oxidation (passive oxidation and active regeneration) with the experimental results presented in references $[6,7]$.

5. Develop uniformity index (UI) analysis methodology to describe temperature and PM distribution from the model.

6. Compare and analyze the temperature UI and PM loading UI differences of passive oxidation and active regeneration experiments.

7. Analyze the data to determine the influence of fuel type on PM oxidation rate, temperature, and regeneration time.

\section{Literature Review}

The literature review is organized into two parts. First, prior research work in the area of multi-dimensional temperature and PM distribution modeling is presented. Then, a review of experimental investigations related to PM distribution is provided.

\subsection{Multi-Dimensional Temperature and PM Distribution Modeling Efforts}

Konstandopoulos et al. [8] developed a continuum-based multichannel model and used varying PM loading distribution profiles to study PM loading non-uniformities and their effect on the regeneration process (duration and maximum filter temperature). This study shows that the regeneration time was shorter (20-30\% faster regeneration) when the filter was loaded more towards the front compared to the uniform loading case for an identical total PM loading. The maximum filter substrate temperature between both cases (more loading at front versus uniform loading) was close to each other. Yi [9] developed a 3-D macroscopic model to simulate PM loading distribution within the filter. This study shows that the PM accumulation is more near the centerline of the filter compared to other sections due to the higher exhaust flow rate at the 
center section for the given test geometry. Ranalli et al. [10] also showed similar findings with 3-D computational fluid dynamics (CFD) simulations that PM loading is maximum at the central regions of the filter attributing it to higher mass flow rate and flow velocity in that section compared to other places for the given test geometry. Kostoglou et al. [11] used the continuum-based multichannel model to illustrate how PM regeneration is affected by the non-uniformities in inlet flow and temperature, local hot spots, and heat losses from a filter can. The study shows that, with the non-insulated filter can and with radially uniform flow and temperature conditions, the regeneration efficiency is lower at the outer surfaces of the filter due to lower exhaust gas temperature (caused by the thermal boundary layer). Koltsakis et al. [12] presented a comprehensive summary of 3-D filter modeling and used PM loading distribution plots to highlight the effect of flow maldistribution on filter loading. The 1-D model in reference [13] simulated the axial variation in PM cake layer thickness assuming the PM deposition rate is proportional to wall flow velocity and showed the increased PM cake layer thickness towards end of CPF compared to other sections for the passive oxidation (PO) and active regeneration (AR) cases studied in the reference [13]. The 1-D model developed in reference [13] also needed a correction to the input data while simulating the AR engine experimental data. This is mainly to account for the temperature and PM maldistribution of CPF. The authors believe this model of the diesel particulate filter (DPF) [1] along with the extensive comparison to experimental data provide significant contribution to the modeling literature because it can be used in an ECU and for design computations and it has the potential to overcome the problem of the 1-D model not being able to predict delta $\mathrm{P}$ under AR transient conditions as was shown by Premchand et al. [13] and Premchand [14].

\subsection{Experimental Investigations of PM Distribution in Filter}

Several experimental techniques have been developed to determine PM distribution within the filter. They include both destructive and non-destructive methods. The non-destructive methods are advantageous as they allow for repeat tests. Ranalli et al. [10] developed a methodology for a qualitative assessment of radial PM distribution of a loaded filter using Laser Doppler Anemometer (LDA) analysis and thermographic analysis. This method was not capable of analyzing the axial PM distribution within the filter substrate. The LDA analysis of the loaded filter showed that the low flow and velocity test conditions yield uniform loading of the filter and the higher flow and velocity conditions resulted in nonuniform loading. Pinturaud et al. [15] used velocity profiles determined from the anemometer to show the radial PM distribution. Based on the experimental study, during loading and active regeneration, the PM distribution is uniform in the radial direction. The radial PM distribution is more uniform at lower filter loading $(<0.7 \mathrm{~g} / \mathrm{L})$ and it was "quasi-uniform" at the higher level of loading $(6.6 \mathrm{~g} / \mathrm{L})$. This was attributed to the cone in front of the filter causing more PM loading (flow and velocity) towards the center of the filter compared to other surfaces radially. The axial PM distribution studies were also carried out using scanning electron microscopy (SEM). The study shows that PM cake loading is maximum at the end of the channel and minimum at the entrance. The PM loading of $>1.3 \mathrm{~g} / \mathrm{L}$ shows a transition from deep bed filtration to cake filtration. The axial PM distribution tends to become more uniform at higher loading compared to lower loading. The study also shows that during active regeneration, the PM oxidation tends to homogenize the PM distribution along the axial direction. Bensaid et al. [16] carried out an experimental study using field emission scanning electron microscopy (FESEM) to determine the axial and radial PM distribution of a whole DPF during the loading process. The study shows that the PM cake layer thickness along the radial direction is affected by the inlet pipe geometry due to the inlet flow distribution. Foley et al. [17] developed a methodology to quantify the 3-D PM distribution measured using a terahertz wave scanner which is used as the reference in this paper to compare PM loading trends predicted by the MPF model. Unlike the SEM measuring technique, the terahertz wave scanner is the non-destructive experimental techniques available to quantify 3-D PM distributions within the filter and hence reducing the experimental variations.

From the above review, it is evident that the PM distribution within the filter is non-uniform and the distribution varies based on inlet flow and velocity distribution, radial temperature distribution (up to $40{ }^{\circ} \mathrm{C}$ observed in this study during PM oxidation by passive oxidation and active regeneration), and the axial porous wall velocity. The non-uniform temperature distribution affects the PM distribution within the filter, regeneration efficiency and hence durability of the CPF. The MPF model that could be developed for an engine electronic control unit (ECU) application was presented in reference [1] and showed good capability to predict temperature and PM distribution within the CPF.

In this research, the MPF model from our previous work [1] was extended to include temperature and PM loading uniformity index analysis of the CPF. There were eighteen experimental runs comprised of ULSD, B10, and B20 fuels. The model simulation results were compared with experimental results presented in references [2-5] for PM mass retained and temperature distribution. The PM distribution simulated by the MPF model was also compared with terahertz wave scanner PM distribution data presented in references $[6,7]$. The details of experimental data used for the model validation is presented in Section 3. 


\section{Experimental Data}

The experimental study was carried out on the Cummins $272 \mathrm{~kW} 2007$ ISL engine with diesel oxidation catalyst (DOC) and CPF aftertreatment devices. Experimental data collected by Shiel et al. [2, 4] and Pidgeon et al. [3, 5] at eighteen different operating conditions was used to calibrate the model developed in reference [1].

The specifications of the engine and aftertreatment system are shown in Tables 1 and 2, respectively. The test summary of eighteen test runs used in this study is shown in Table 6 (six passive oxidation experiments) and Table 7 (twelve active regeneration experiments) in Appendix 1. The experiments were performed with three fuels-ULSD, B10, and B20 blends. The properties of test fuels used for the experiments are documented in references $[2,3]$.

\subsection{Passive Oxidation Experiments}

An overview of the passive oxidation experimental test procedure is shown in Fig. 1. The passive oxidation experiment starts with the CPF clean out phase where the engine was operated at active regeneration test condition $\left(600^{\circ} \mathrm{C}\right.$ for 15 min to cleanup CPF) followed by stage 1 loading of filter with a DOC inlet temperature of $265+/-10{ }^{\circ} \mathrm{C}$ for $30 \mathrm{~min}$. Then, the stage 2 loading starts after weighing of the filter at the end of stage 1 . The engine operating conditions for stage 2 loading is the same as stage 1 . The stage 2 loading continues to achieve a target filter loading of $2.2+/-0.2 \mathrm{~g} / \mathrm{L}$. At the end of stage 2 loading, the filter was weighed again and the test was continued further with the ramp up (RU) phase for $15 \mathrm{~min}$ before switching to the passive oxidation phase to achieve a stable filter temperature for PM oxidation. The engine operating conditions for the RU phase is the same as those in stages 1 and 2 loading conditions. The purpose of the RU phase is to achieve similar substrate temperature as stage 1 and stage 2 loading before PM oxidation. During the stage $2 \mathrm{CPF}$ weighing process, the $\mathrm{CPF}$ temperature is dropped to a lower value and hence, after reinstalling the CPF in the engine, the

Table 1 Specifications of engine [2, 3]

\begin{tabular}{ll}
\hline Model & $\begin{array}{l}\text { Cummins ISL }-272 \mathrm{~kW}(365 \mathrm{HP}) \\
\text { and } 317 \mathrm{~kW}(425 \mathrm{HP})\end{array}$ \\
\hline Year of manufacture & 2007 \\
Cylinders & 6, inline \\
Bore $\times$ stroke & $115 \times 144.5 \mathrm{~mm}$ \\
Displacement volume & $8.9 \mathrm{~L}$ \\
Aspiration & Turbocharged \\
Aftercooling & Charge air cooler \\
Rated speed and power & $2100 \mathrm{RPM}$ and $272 \mathrm{~kW}$ \\
Peak torque & $1695 \mathrm{Nm} @ 1400 \mathrm{RPM}$ \\
\hline
\end{tabular}

Table 2 Specifications of the after treatment system used in the experiments $[2,3]$

\begin{tabular}{llll}
\hline & DOC & CPF & Units \\
\hline Substrate material & Cordierite & Cordierite & - \\
Cell geometry & Square & Square & - \\
Diameter & 267 & 267 & $\mathrm{~mm}$ \\
Length & 102 & 305 & $\mathrm{~mm}$ \\
Total volume & 5.7 & 17.1 & $\mathrm{~L}$ \\
Cell density & $62(400)$ & $31(200)$ & $\mathrm{cells} \mathrm{cm}{ }^{-2}\left(\mathrm{cells} \mathrm{in}^{-2}\right)$ \\
Cell width & 1.09 & 1.49 & $\mathrm{~mm}$ \\
Frontal area & 81 & 69 & $\%$ \\
Channel wall thickness & 0.114 & 0.305 & $\mathrm{Mm}^{-3}$ \\
Wall density & NA & 0.45 & $\mathrm{~g} \mathrm{~cm}^{-3}$ \\
Specific heat & NA & 891 & $\mathrm{~J} \mathrm{~kg}^{-1} \mathrm{~K}^{-1}$ \\
Thermal conductivity & NA & 0.84 & $\mathrm{~W} \mathrm{~m} \mathrm{~K}^{-1}$ \\
Porosity & 35 & 52 & $\%$ \\
Mean pore size & NA & 13 & $\mu \mathrm{m}$ \\
\hline
\end{tabular}

engine was operated at RU phase (engine operating conditions same as stage 2) for $15 \mathrm{~min}$ to achieve a similar stable temperature as stage 2 loading condition before switching to the passive oxidation phase. Following the RU phase, the engine was operated at the passive oxidation test conditions (engine speed and load at which there is a significant PM, nitrogen dioxide $\left(\mathrm{NO}_{2}\right) / \mathrm{NO}_{\mathrm{x}}$ ratio, and temperatures $>300{ }^{\circ} \mathrm{C}$ ) for a predetermined duration and at the temperatures listed in Table 6 in Appendix 1. Upon completion of the passive oxidation phase, the engine was operated at stage 3 loading conditions (engine conditions are the same as stage 1 and 2) for $30 \mathrm{~min}$ and then the filter was weighed to determine the filter weight. Then, the test was continued further with stage 4 loading for $60 \mathrm{~min}$ and then the filter was weighed again to determine the post-loading weight of the filter. The experimental data from these tests (temperature distribution, PM loading) are used in this study for the validation of the MPF model of

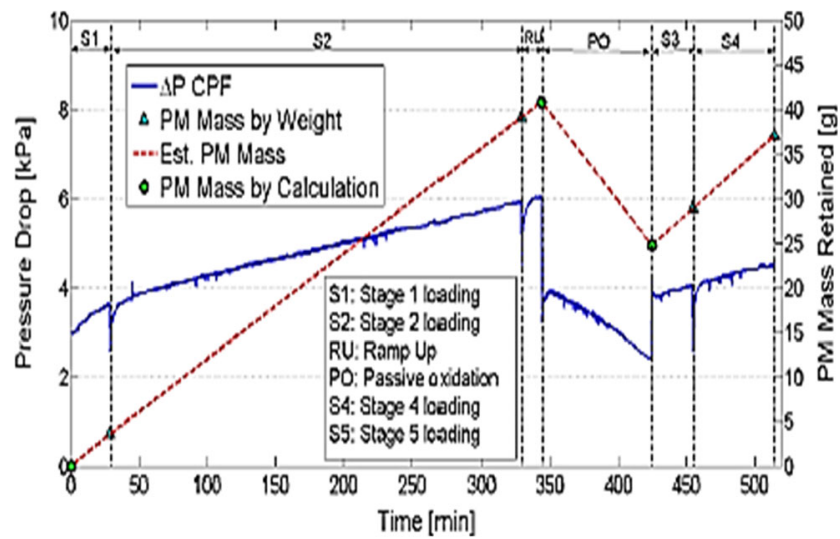

Fig. 1 Overview of the stages of the passive oxidation experiments in this study-adapted from reference [2] 


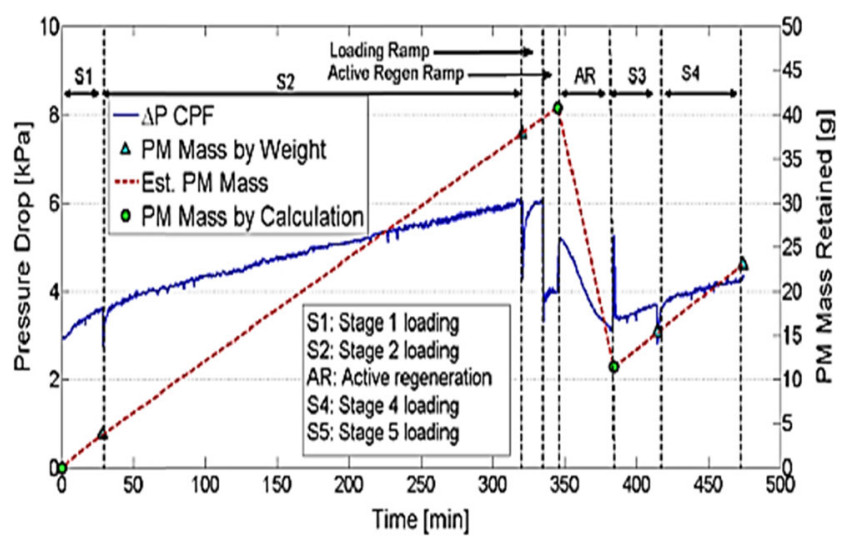

Fig. 2 Overview of the stages of the active regeneration experiments in this study-adapted from reference [3]

the $\mathrm{CPF}$ and for the analysis of the kinetic parameters of the model for $\mathrm{NO}_{2}$ assisted $\mathrm{PM}$ oxidation.

\subsection{Active Regeneration Experiments}

An overview of the active regeneration experimental test procedure is shown in Fig. 2. The CPF clean out phase, stage 1-2 loading, RU of $15 \mathrm{~min}$, and stages 3-4 loading are similar to the passive oxidation experimental data. In the RU, the engine was operated at stage 2 loading conditions for 15 min or until the DOC inlet temperature has stabilized at $265 \pm 10^{\circ} \mathrm{C}$ and then the active regeneration ramp phase for $10 \mathrm{~min}$ or until the DOC inlet temperature has stabilized at $325 \pm 10{ }^{\circ} \mathrm{C}$ to stabilize the $\mathrm{CPF}$ temperature prior to active regeneration. The active regeneration phase was continued for a predetermined amount of time at the specified CPF inlet temperatures listed in Table 7 in Appendix 1. If the active regeneration was allowed to continue for a longer period of time other than the specified durations in Table 7 , then there would not be enough PM within the CPF to obtain an accurate PM mass retained measurement.

\subsection{CPF Temperature Distribution}

The MPF model was validated using the experimental temperature distribution data recorded for the experimental studies in references [4, 5]. The CPF thermocouple layout used for the temperature distribution measurements is shown in Fig. 3. The detailed specifications of the thermocouples are shown in Table 8 in Appendix 1.

\section{MPF Model Overview}

The MPF model developed in reference [1] by the same authors is used for this research. The MPF model works on the principle of resistance node methodology to determine the temperature at each node using the neighboring node values. The model has four sets of input variables; (i) instantaneous exhaust mass flow rate $(\dot{m})$, (ii) $\mathrm{CPF}$ inlet concentrations $\left(C_{P M}, C_{N O 2}\right.$, and $\left.C_{O 2}\right)$, (iii) $\mathrm{CPF}$ inlet temperature $\left(T_{i n}\right)$, and (iv) $\mathrm{CPF}$ inlet gas pressure $\left(P_{i n}\right)$. In addition, the model has 15 constants and 7 calibration parameters as documented in reference [1]. Using the set of inputs, model constants, and calibration parameters, the model simulates the time varying temperature and PM loading distribution within the CPF from node to node. An explicit finite difference solver is used to determine the temperature at each time step $(0.01 \mathrm{~s})$ from previous time step values. The model inputs are sampled at $0.2 \mathrm{~Hz}$. In the MPF model, the CPF is modeled as a user configurable number of axial and radial zones as shown in Fig. 4.
Fig. 3 CPF thermocouple layout $[4,5]$
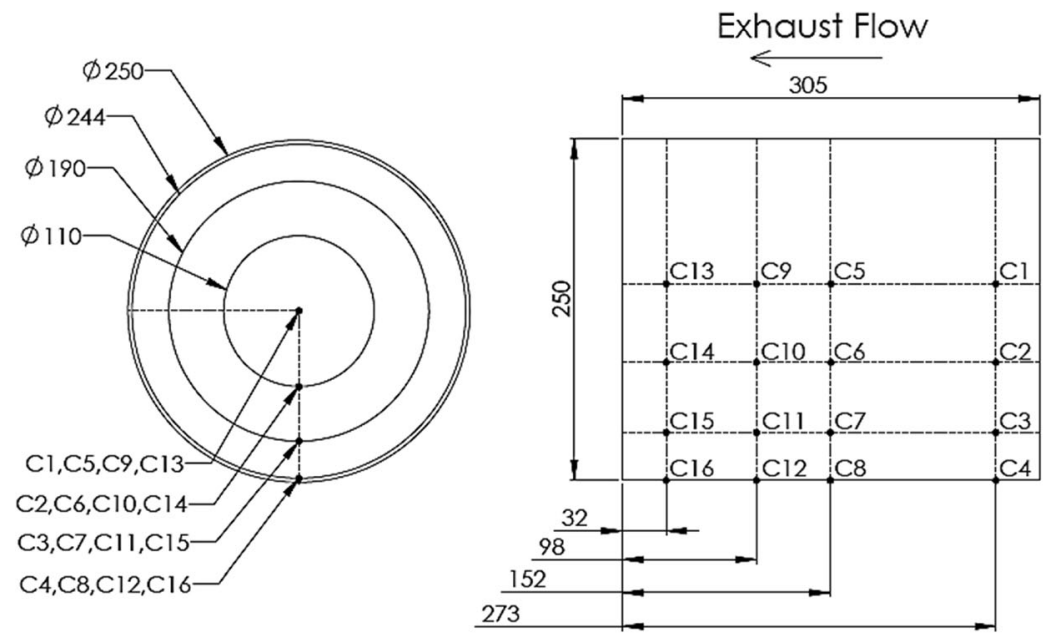


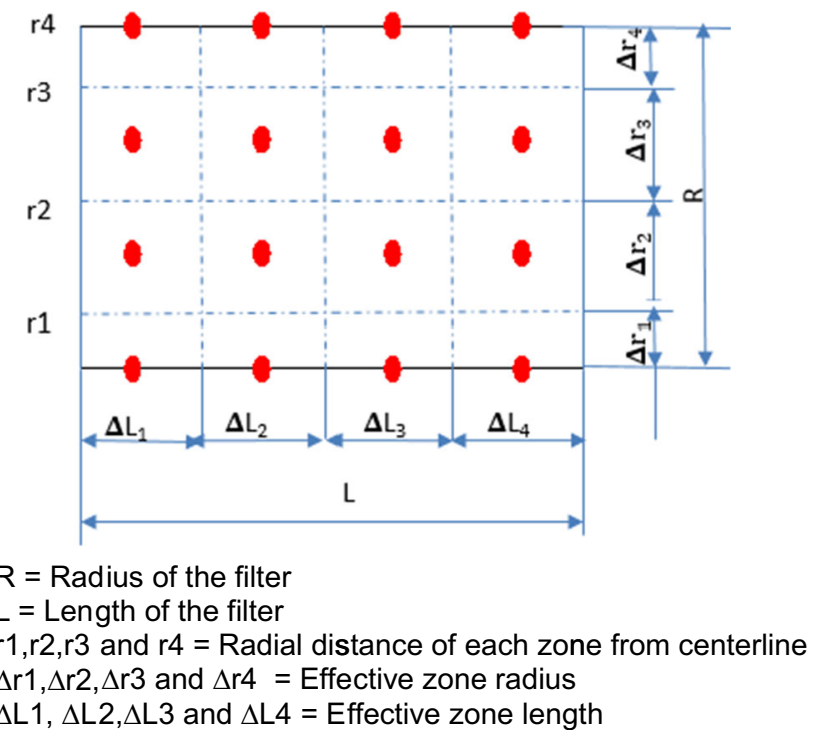

Fig. 4 Multi-zone CPF model schematic shown for $4 \times 4$ zone configuration

The filter and gas energy Eq. (1) is employed at each zone,

$$
\begin{aligned}
& \left(\rho_{s} c_{s} V s_{i, j}+\rho_{f} c_{f} V_{f_{i, j}}\right) \quad \frac{d T_{f_{i, j}}}{d t}= \\
& Q_{\text {cond.axial }}+Q_{\text {cond.radial }}+Q_{\text {conv }}+Q_{\text {reac }}+Q_{\text {rad }}
\end{aligned}
$$

where $T_{f}$ is the filter substrate temperature.

The detailed formulation for the terms used in Eq. (1) is explained in reference [1].

In the MPF model, PM oxidation by $\mathrm{NO}_{2}$ assisted and thermal (oxygen $\left(\mathrm{O}_{2}\right)$ ) mechanisms are included. The CPF inlet temperature variation is accounted for using the thermal boundary layer equations. The CPF heat transfer is modeled using conduction, convection, and radiation equations. The MPF model presented in reference [1] was calibrated using the 18 experimental runs from references [3-5] using a twostep calibration process. The detailed model development equations and model calibration process is explained in reference [1].

\section{Model Discretization Study}

A parametric study was carried out to determine the optimum required number of zones in the MPF model in the range of $5 \times 5$ to $20 \times 20$ zones for aftertreatment control applications. The filter substrate temperatures during active regeneration $\left(450-600{ }^{\circ} \mathrm{C}\right)$ are higher than the passive oxidation $(250$ $\left.400{ }^{\circ} \mathrm{C}\right)$. The high temperatures during active regeneration results in increased temperature distribution (AR-B10-1 experiment: average temperature during active regeneration: $530^{\circ} \mathrm{C}$, radial temperature distribution $\cong 40^{\circ} \mathrm{C}$, axial temperature distribution $\cong 12^{\circ} \mathrm{C}$ ), and highly non-uniform PM distribution within the filter. Hence, one of the active regeneration experiments (AR-B10-1 experiment listed in Table 7) was used as a reference experiment for the discretization study. The MPF model used the model constants, PM kinetic parameters, heat transfer coefficients, and filter density parameters developed in reference [1] for all three cases $(5 \times 5,10 \times 10$ and $20 \times 20$ zones).

An explicit solver-based finite difference approach is used to solve the temperature at each time step. The explicit solver time step was $0.01 \mathrm{~s}$ to achieve numerical stability up to the $20 \times 20$ zone model. The simulation model time step was set to $5 \mathrm{~s}$ (fixed time step) over the total test duration of approximately $7.33 \mathrm{~h}(26390 \mathrm{~s})$ for the AR-B10-1 experiment. The total test duration varies with experiment.

Figure 5 shows the model discretization size versus real time factor for the AR-B10-1 experiment. The real time factor is calculated as the ratio of model run time to the real time of the experiment. The real time factor of 1 indicates that the model runs as fast as real time. From Fig. 5, the real time factor significantly increases with increasing the discretization size. In addition, the real time factor increases linearly as a function of total number of elements ( 25 nodes for $5 \times 5$ model, 100 nodes for $10 \times 10$ model, and 400 nodes for $20 \times 20$ model). The lowest real time factor is for the $5 \times 5$ zone model in which the MPF model takes $3.9 \%$ of total real time or about 25 times faster than the real time. It is important to note that the MPF model was run on a laptop computer with the specifications of 12 GB RAM, 64 bit, and Intel core i7 processor. The typical ECU used on engine applications [18] have 32 bit and $200 \mathrm{MHz}$ processors. However, Matlab is a high level programming language and it is approximately $10 \times$ slower than the $\mathrm{C}$ language that closely mirrors the assembly language that processors commonly use. Depcik and Assanis [19] showed that for a sample problem presented in reference [19], the C code runs $18.1 \times$ faster than the Matlab code. Hence, with an optimized C code, the MPF model with low computational requirement like the $5 \times 5$ and $10 \times 10$ zone shows high

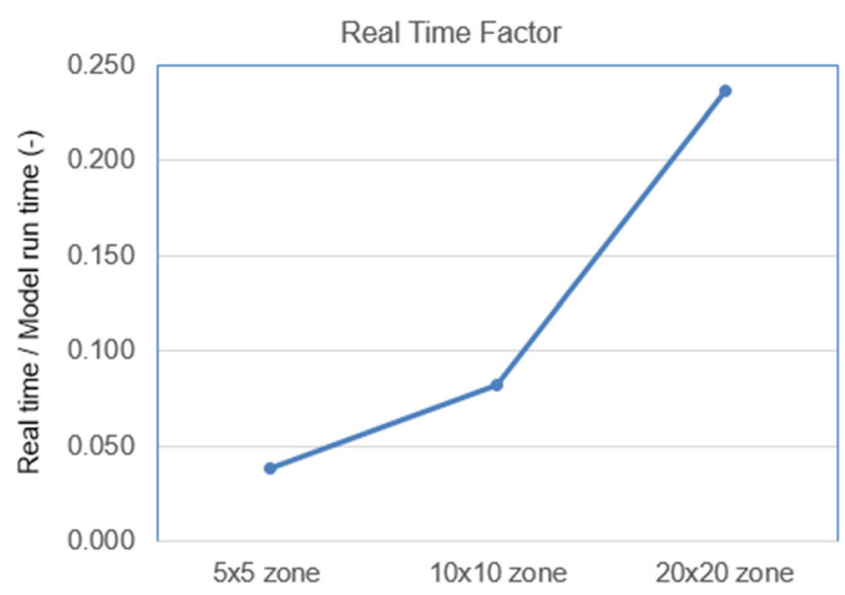

Fig. 5 Model discretization size versus real time factor - for the ARB10-1 experiment 
potential to run as part of a conventional ECU or a dedicated ECU that manages CPF functions exclusively.

Further, Fig. $6 \mathrm{a}, \mathrm{b}$ shows the real time factor for the individual time steps for two repeat runs (run 1 and run 2) of the $10 \times 10$ zone model. The $10 \times 10$ zone model was used as a reference for this study because it shows better trade-off for computational efficiency and accuracy as shown later in this section. From Fig. 6a, the maximum real time factor is less than 0.12 and most of the steps run with the real time factor of $\cong 0.08$. Similarly, from Fig. $6 \mathrm{~b}$, the maximum RT factor is less than 0.17 and most of the steps run with RT factor of $\cong 0.08$. The differences in maximum real time factor values between run 1 and run 2 ( 0.12 versus 0.17$)$ may be from the differences in PC run times because of the back ground process not from the MPF model. From Figs. 6a, b, the MPF model runs real time in each time step with the maximum real time factor in the range of 0.12 to 0.17 and most of the points run with the real time factor of 0.08 . Considering the small real time factor $(<0.17)$, the $10 \times 10$ zone MPF model shows good capability to run within the ECU in real time.
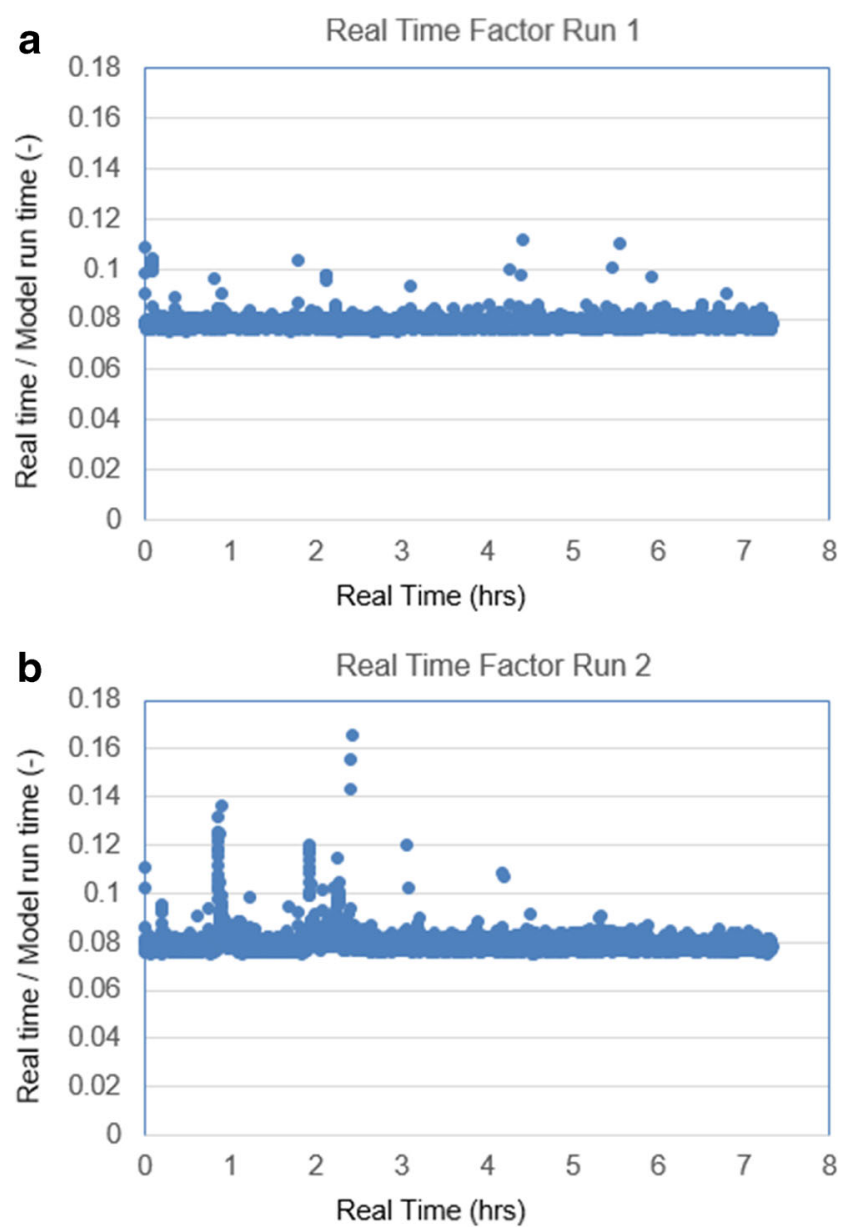

Fig. 6 a Real time factor of individual time steps for the AR-B10-1 experiment $-10 \times 10$ zone model (run1). b Real time factor of individual time steps for the AR-B10-1 experiment-10×10 zone model (run 2)
Figure 7 shows the model discretization size versus PM mass loading during the AR-B10-1 experiment. From Fig. 7, the $10 \times 10$ zone model shows close agreement $(<0.3 \mathrm{~g}$ at the end of post-loading) with the experimental data. The $5 \times 5$ zone and $20 \times 20$ zone models underpredict the PM loading by 0.9 and $0.7 \mathrm{~g}$, respectively, at the end of post-loading (at $7.3 \mathrm{~h})$.

Figure $8 \mathrm{a}, \mathrm{b}, \mathrm{c}$ show the PM loading distribution with three levels of MPF model discretization $(5 \times 5,10 \times 10$, and $20 \times 20$ zones). From Fig. 8a, b, c, the PM loading distribution below radiuses of $60 \mathrm{~mm}$ are close to one another. The PM distribution contours are showing slightly different shapes, and relative positions are slightly different between the discretization sizes. However, the actual PM distribution differences are small (within $0.1 \mathrm{~g} / \mathrm{L}$ ). This is mainly because the temperature distribution is approximately uniform (within $10^{\circ} \mathrm{C}$ ) along the radial direction up to the filter radiuses of $60 \mathrm{~mm}$ as shown later and hence, the discretization size is not affecting the PM loading distribution. The temperature gradient increases significantly over filter radiuses $60 \mathrm{~mm}\left(\cong 40^{\circ} \mathrm{C}\right)$. The $10 \times 10$ zone and $20 \times 20$ zone models show similar filter loading over $60 \mathrm{~mm}$ radiuses with the maximum filter loading of $2.4 \mathrm{~g} / \mathrm{L}$. The $5 \times 5$ zone model underpredicts PM loading by $\cong 0.4 \mathrm{~g} / \mathrm{L}$ at $R=133 \mathrm{~mm}$. From Fig. $8 \mathrm{a}, \mathrm{b}$, c, the $5 \times 5$ zone MPF model underpredict PM loading ( $\cong 0.4 \mathrm{~g} / \mathrm{L}$ at $R=133 \mathrm{~mm}$ ) compared to the $10 \times 10$ and $20 \times 20$ zone MPF model, because of the coarse discretization in axial and radial direction whereas the $10 \times 10$ and $20 \times 20$ zone models shows close agreement $(<0.2 \mathrm{~g} / \mathrm{L})$ with one another. To compare the accuracy of the temperature estimates between the discretization sizes, the root mean square (RMS) temperature error was determined from the measured and simulated substrate temperatures at C1-C16 thermocouple locations. The RMS temperature error

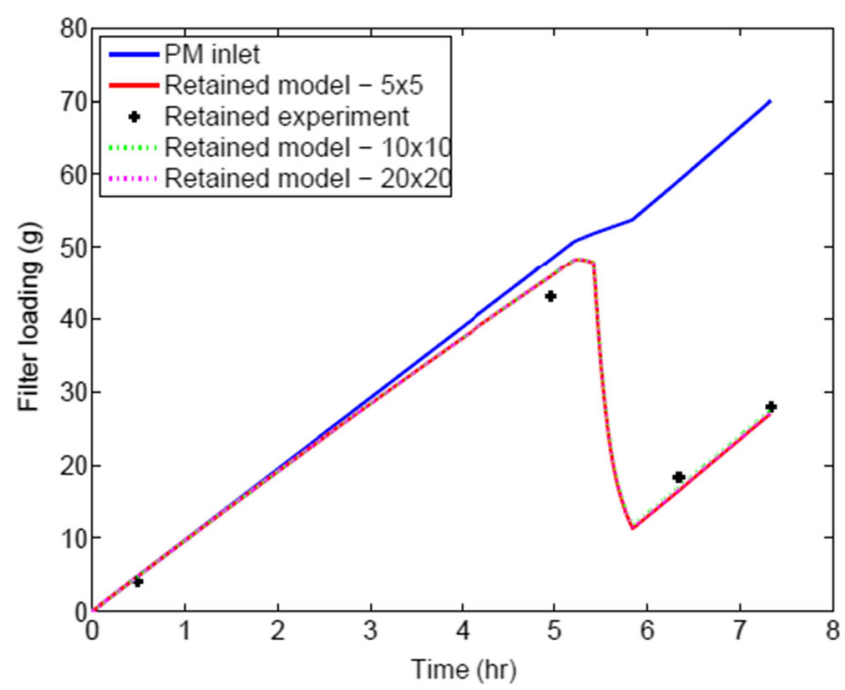

Fig. 7 Comparison of PM mass retained in the experimental data and MPF simulation model along with the PM inlet rate for $5 \times 5,10 \times 10$ and $20 \times 20$ zones (AR-B10-1 experiment) 

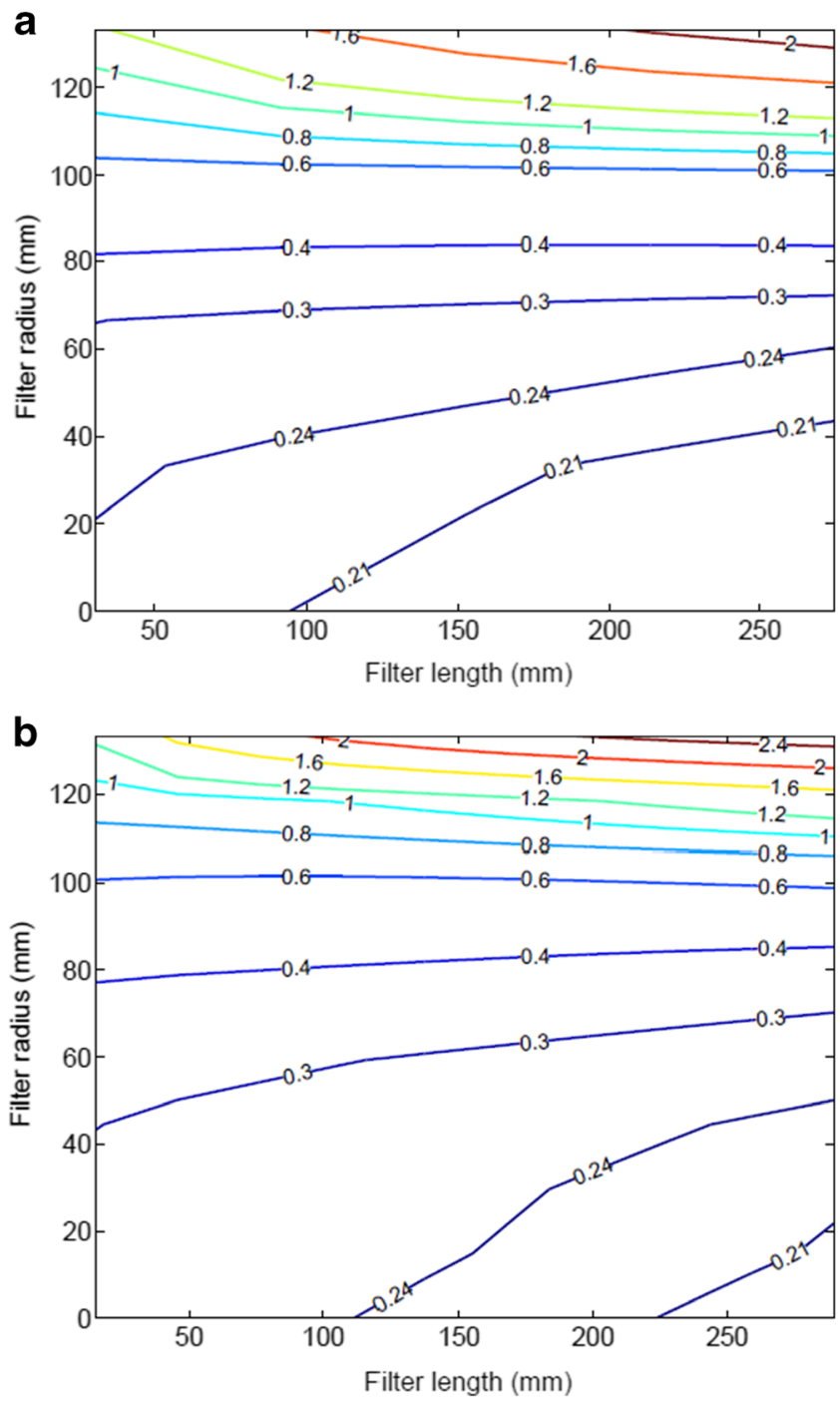

Fig. 8 a $5 \times 5$ zone model results for simulated PM mass loading distribution along axial and radial directions at the end of PM oxidation by active regeneration @ 5.82 h (AR-B10-1 experiment). b 10×10 zone model results for simulated PM mass loading distribution along axial and radial directions at the end of PM oxidation by active regeneration @

was comparable (within $2{ }^{\circ} \mathrm{C}$ ) among $5 \times 5,10 \times 10$, and $20 \times$ 20 zone models.

Table 3 summarizes the model accuracy versus computational time of the MPF model with three discretization levels and indicates that the $10 \times 10$ zone model offers the better trade-off compared to $5 \times 5$ and $20 \times 20$ zone models. In

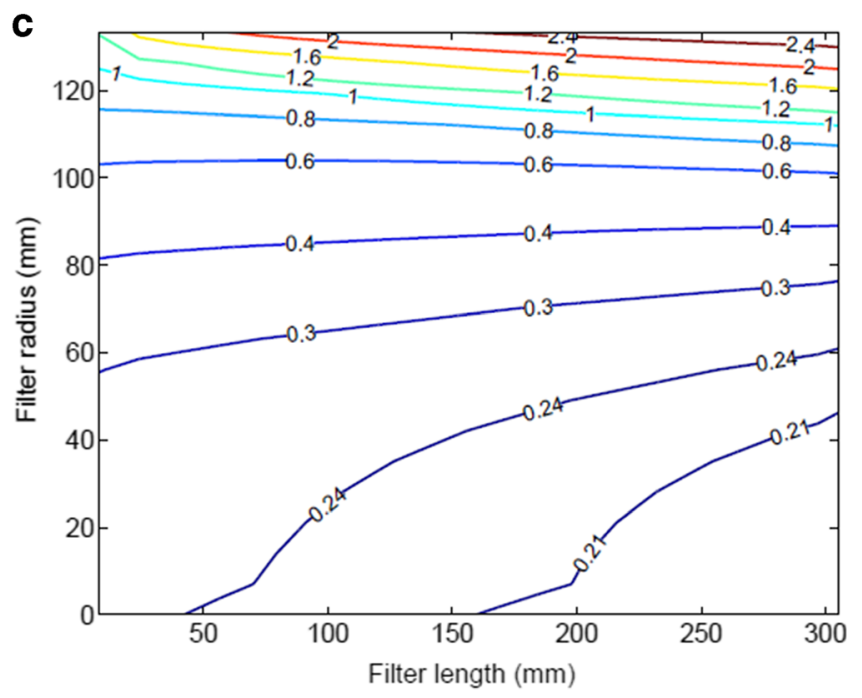

$5.82 \mathrm{~h}$ (AR-B10-1 experiment). c $20 \times 20$ zone model results for simulated PM mass loading distribution along axial and radial directions at the end of PM oxidation by active regeneration @ 5.82 h (AR-B10-1 experiment)

addition, using the $10 \times 10$ zone model allows further margin for future coding expansion related to the species concentration solver. An explicit finite difference solver is used to determine species concentrations. This solver requires further smaller time steps $(<0.01 \mathrm{~s})$ for stability because of the advection terms in the chemical species equations which would
Table 3 MPF model discretization summarytemperature, PM loading, and computational time trade-off

\begin{tabular}{llll}
\hline $\begin{array}{l}\text { Model discretization } \\
\text { level }\end{array}$ & $\begin{array}{l}\text { RMS temperature error } \\
\text { @ end of post-loading } \\
\text { (time 7.3 h) } \\
{ }^{\circ} \mathrm{C}\end{array}$ & $\begin{array}{l}\text { PM loading error @ } \\
\text { end of post-loading } \\
\text { (time } 7.3 \mathrm{~h} \text { ) } \\
\mathrm{g}\end{array}$ & $\begin{array}{l}\text { Simulation time/real } \\
\text { time }[-]\end{array}$ \\
\hline $5 \times 5$ zone & 1.9 & -0.9 & 0.039 \\
$10 \times 10$ zone & 2.4 & -0.3 & 0.082 \\
$20 \times 20$ zone & 2.0 & -0.7 & 0.236 \\
\hline
\end{tabular}


further slowdown the computation especially for the $20 \times 20$ model. Thus, the $10 \times 10$ zone model was selected as the optimum model configuration for this study. The simulation results in the rest of the paper are using the $10 \times 10$ zone MPF model.

Using the $10 \times 10$ zone MPF model, all 18 runs were simulated. A single set of model constants, PM kinetic parameters based on fuel type and heat transfer coefficients from reference [1], are used for all 18 runs. Detailed comparison of the experimental data and MPF model results for PM mass retained is provided in Table 9, Appendix 2. The maximum absolute error for the end of stage 4 of PM loading is $3.8 \mathrm{~g}$ for PO-B10-17 experiment, and the RMS error considering all 18 experiments were less than $2.1 \mathrm{~g}$. In the following section, the detailed analysis of the MPF model results with experimental data for ULSD, B10, and B20 fuels are presented.

\section{Results and Discussion}

\subsection{Analysis of PM Kinetics Parameters}

The MPF model was parameterized using the same two-step calibration process in reference [1]. The PM oxidation in the MPF model includes thermal $\left(\mathrm{O}_{2}\right)$ and $\mathrm{NO}_{2}$ assisted PM oxidation. The overall PM oxidation $\left(d \frac{\left(m s_{i, j}\right)}{d t)}\right.$ by thermal $\mathrm{O}_{2}$ and $\mathrm{NO}_{2}$ assisted PM oxidation in the MPF model is given as [12, 20]:

$\frac{d\left(m s_{i, j}\right)}{d t}=-\frac{S_{p} \rho Y_{i, j} \mathrm{O}_{2} k_{\mathrm{O}_{2}} W_{c}}{\alpha_{\mathrm{O}_{2}} W_{\mathrm{O}_{2}} \rho_{s}} m s_{i, j}-\frac{S_{p} \rho Y_{i, j \mathrm{NO}_{2}} k_{\mathrm{NO}_{2}} W_{c}}{\alpha_{\mathrm{NO}_{2}} W_{\mathrm{NO}_{2} \rho_{s}}} m s_{i, j}$

where $\alpha_{\mathrm{O}_{2}}$ and $\alpha_{\mathrm{NO}_{2}}$ are the indexes of the completeness of the reactions characterizing the selectivity towards $\mathrm{CO}$ or carbon dioxide $\left(\mathrm{CO}_{2}\right)$ production.

The Arrhenius reaction rates $\left(k_{O_{2}}\right.$ and $\left.k_{\mathrm{NO}_{2}}\right)$ are given as:

$k_{O_{2}}=A_{o_{2}} T f_{i, j} \exp \left[-E_{o_{2}} /\left(R_{u} T f_{i, j}\right)\right]$

$k_{\mathrm{NO}_{2}}=A_{N O_{2}} T f_{i, j} \exp \left[-E_{\mathrm{NO}_{2}} /\left(R_{u} T f_{i, j}\right)\right]$

where $T f_{i, j}$ is the temperature of combined filter and PM cake at each zone (i, j).
Table 4 show the calibrated PM kinetic parameters for ULSD, B10, and B20 fuels.

The following section shows the analysis of PM kinetic parameters using Arrhenius plots for ULSD, B10, and B20 fuels during $\mathrm{NO}_{2}$ and thermal $\left(\mathrm{O}_{2}\right)$ assisted $\mathrm{PM}$ oxidation.

Figure 9 shows the plot of natural logarithms of individual $\mathrm{NO}_{2}$-assisted reaction rate constants plotted against the inverse of the average absolute temperature measured during passive oxidation phase of the experiment (Arrhenius reaction rates). The $\mathrm{NO}_{2}$-assisted reaction rate constant determines the rate of PM oxidation reaction and it depends on the passive oxidation temperature shown in Table 6, Appendix 1. From Fig. 9, three distinct reaction rates can be determined for each fuel type. The natural logarithms of reaction rate increases as a function of temperature linearly for B10 fuel. On comparing the activation energies between fuels (Table 4), B10 fuel shows lower reaction rate at a given temperature compared to B20 and ULSD fuels. The B10 fuel shows $5.4 \%$ higher activation energy, and B20 shows $3.8 \%$ higher activation energy compared with ULSD fuel. Due to the lack of experimental data for passive oxidation experiments for ULSD fuel type, the PM kinetics for ULSD fuel were determined by simulating the stage 1-2 loading portion of ULSD active regeneration experiments. On comparing the activation energy determined from Fig. 9 Arrhenius reaction rate analysis with reference [21], Kandylas et al. proposed the activation energy value of $40 \mathrm{~kJ} / \mathrm{gmol}$ for $\mathrm{NO}_{2}$ assisted $\mathrm{PM}$ oxidation reaction with low sulfur content fuel. Further, they also studied the sensitivity of a range of activation energies (from 20 to $80 \mathrm{~kJ} / \mathrm{gmol}$ ) and showed that the model error is less than $1.3 \%$ while assuming $\mathrm{NO}_{2}$ assisted activation energy of $60 \mathrm{~kJ} / \mathrm{gmol}$ as compared to $40 \mathrm{~kJ} / \mathrm{gmol}$. Hence, the activation energy determined in the calibration process is generally in agreement with reference [21].

Figure 10 shows the Arrhenius reaction rates for thermal $\left(\mathrm{O}_{2}\right)$ assisted PM oxidation. From Fig 10, three distinct trends can be observed corresponding to the fuel used during the experiment. In general, the reaction rate increases as a function of temperature for all the fuel types. The B20 fuel shows a higher reaction rate followed by B10 and ULSD fuels. On comparing the activation energies between fuels (Table 4), the activation energy of B20 fuel is $1.9 \%$ lower than the B10 fuel and $5.8 \%$ lower than the ULSD fuel. The activation

Table 4 Calibrated parameters of the MPF model for PM kinetics for three different fuels

\begin{tabular}{|c|c|c|c|c|c|c|}
\hline PM oxidation & Symbol & Description & Units & ULSD & $\mathrm{B} 10$ & $\mathrm{~B} 20$ \\
\hline \multirow[t]{2}{*}{$\mathrm{NO}_{2}$-assisted } & $\mathrm{A}_{\mathrm{NO} 2}$ & Pre-exponential for $\mathrm{NO}_{2}$-assisted $\mathrm{PM}$ oxidation & $\mathrm{m} \mathrm{K}^{-1} \mathrm{~s}^{-1}$ & 0.0088 & 0.0083 & 0.0085 \\
\hline & $\mathrm{E}_{\mathrm{NO} 2}$ & Activation energy for $\mathrm{NO}_{2}$-assisted PM oxidation & $\mathrm{kJ} \mathrm{gmol}^{-1}$ & 60.8 & 64.1 & 63.1 \\
\hline \multirow[t]{2}{*}{ Thermal $\left(\mathrm{O}_{2}\right)$} & $\mathrm{A}_{\mathrm{O} 2}$ & Pre-exponential for thermal $\left(\mathrm{O}_{2}\right)$ PM oxidation & $\mathrm{m} \mathrm{K}^{-1} \mathrm{~s}^{-1}$ & 0.982 & 1.004 & 1.029 \\
\hline & $\mathrm{E}_{\mathrm{O} 2}$ & Activation energy for thermal $\left(\mathrm{O}_{2}\right)$ PM oxidation & $\mathrm{kJ}^{\mathrm{gmol}^{-1}}$ & 158.1 & 151.8 & 148.9 \\
\hline
\end{tabular}


Fig. 9 Arrhenius reaction rates for $\mathrm{NO}_{2}$-assisted $\mathrm{PM}$ oxidation

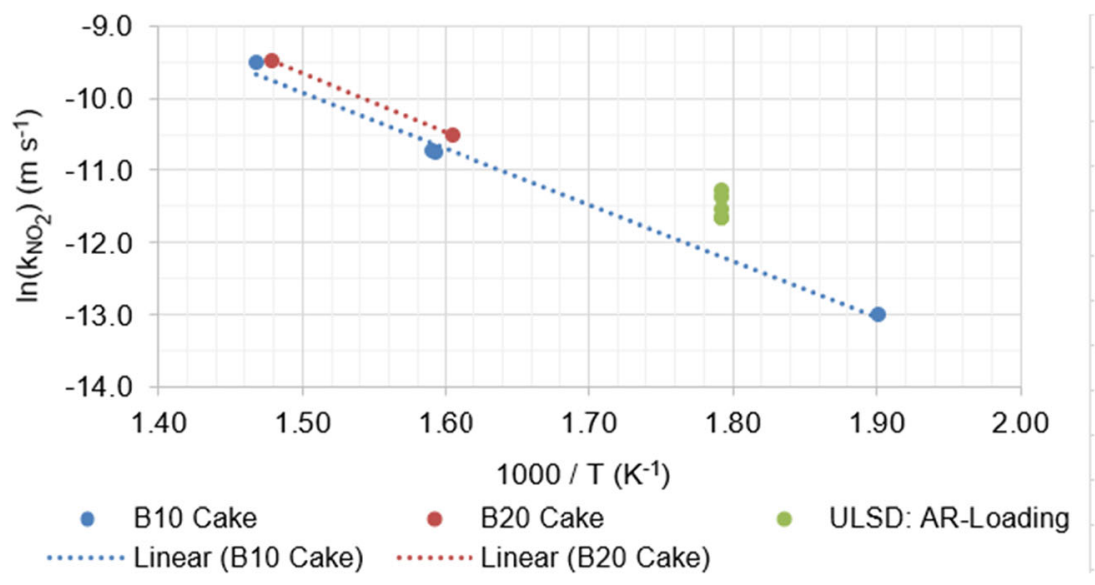

energy determined from the calibration procedure is comparable with the value determined $(152 \pm 5 \mathrm{~kJ} / \mathrm{gmol})$ by Haralampous et al. [22] for thermal $\left(\mathrm{O}_{2}\right)$ assisted PM oxidation from engine experiments.

\subsection{Passive Oxidation Results}

The passive oxidation experimental data used for the model calibration are listed in Table 6 in Appendix 1. From Table 6, the filter substrate temperature during passive oxidation is between 250 and $400{ }^{\circ} \mathrm{C}$. During passive oxidation, most of the PM mass retained in the filter substrate is oxidized by the $\mathrm{NO}_{2}$ assisted $\mathrm{PM}$ oxidation mechanism and it takes 42 to 101 min for PM mass oxidation to complete. This affects the heat transfer, temperature, and filter loading distribution within the filter. This is mainly because of the differences in the reaction rates with $\mathrm{NO}_{2}$ assisted $\mathrm{PM}$ oxidation mechanism (passive oxidation reaction rates are 7.5 to 8.5 times lower than active regeneration reaction rates) and its effect on overall PM loading and temperature distribution. The MPF model accounts for the $\mathrm{NO}_{2}$ assisted PM oxidation using Eqs. 2 to 4. The results of one such passive oxidation experiment is presented in the following section. The comparison of the passive oxidation experiment with the active regeneration experiment in terms of temperature and PM loading distribution is presented later in the paper (Section 6.8).

\subsection{Temperature Distribution}

Figure 11 shows the radial temperature distribution of $\mathrm{PO}-$ B10-15 experiment measured by $\mathrm{C} 1-\mathrm{C} 4$ thermocouples (shown as continuous lines) and the temperatures simulated by the MPF model (shown as dotted lines) at $32 \mathrm{~mm}$ from filter inlet along with the $\mathrm{CPF}$ inlet temperature measured upstream of the CPF. From Fig. 11, the simulation temperature prediction error (absolute) is within $12{ }^{\circ} \mathrm{C}$ excluding the temperature spikes related to the experimental procedure and transition phase of moving in and out of the PO phase of the experiment. The temperature error during the $\mathrm{PO}$ transition phase of the experiment is up to $-15 /+20^{\circ} \mathrm{C}$. This is due to the large temperature gradient during PO transition phase (start and end), and the model takes time to follow the actual temperature increase.

It is important to note that the temperature measured by the thermocouple at location $\mathrm{C} 4$ is the lowest compared to all other thermocouple temperature measurements which can be attributed to the significant temperature drop due to the ambient convection at this location (C4 is located close to the outer
Fig. 10 Arrhenius reaction rates for thermal $\left(\mathrm{O}_{2}\right)$ assisted PM oxidation

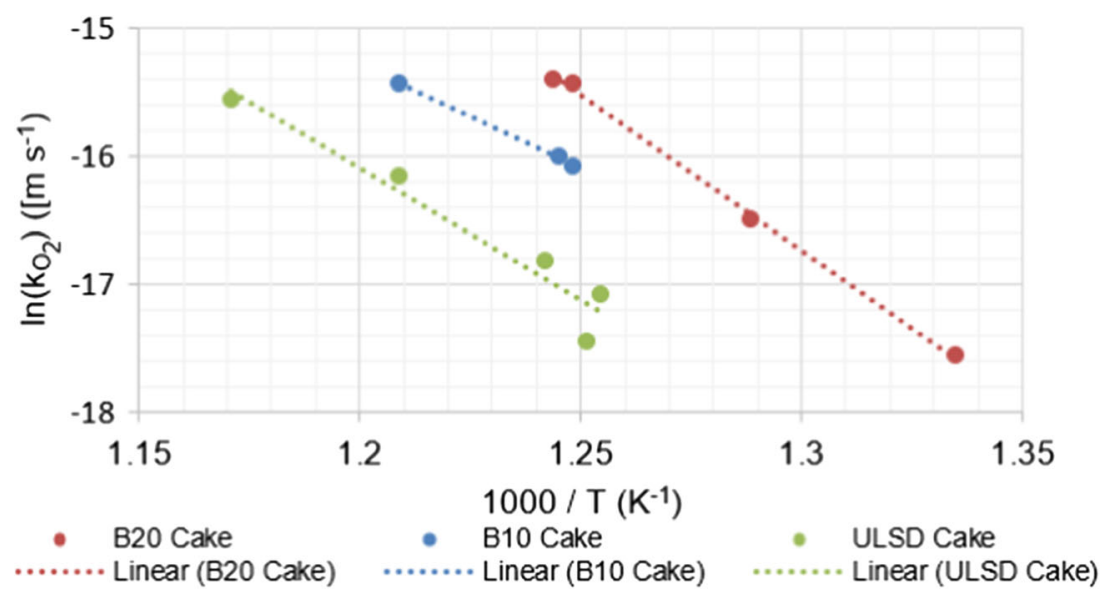




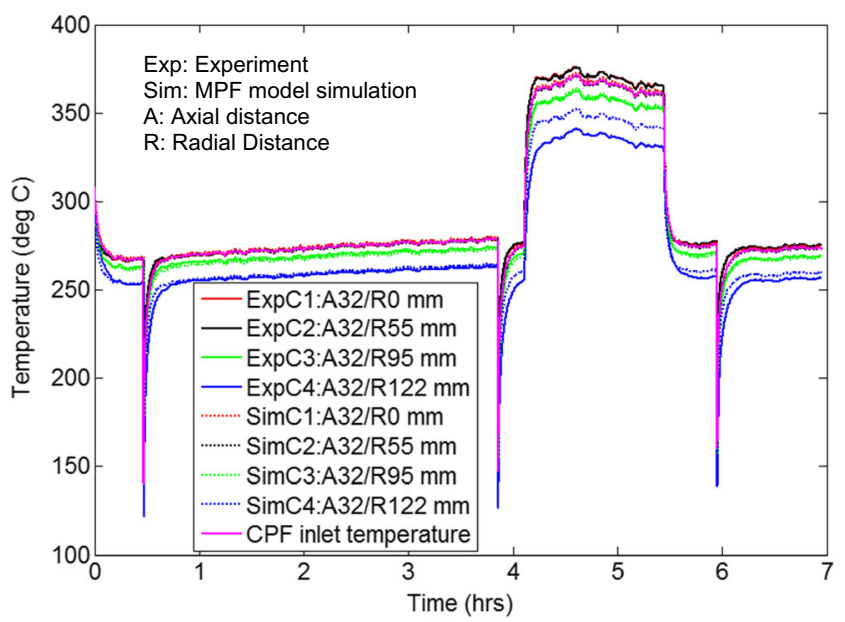

Solid lines: Experimental temperature distribution measured by sixteen thermocouples

Dashed lines: MPF model simulated temperature distribution

Fig. 11 Radial temperature distribution at filter inlet (PO-B10-15 experiment)

wall). Another key observation from Fig. 11 is that the temperature drop in the radially outward direction is due to the convective and radiative heat transfer at the outer surface of the filter wall during the experiment $(0$ to $6.9 \mathrm{~h})$. The MPF model was able to simulate this effect using the thermal boundary layer equations explained in reference [1].

Figure 12 shows the experimental temperature distribution measured by all 16 thermocouples (solid lines) and temperatures simulated by the MPF model (dashed) at $4.36 \mathrm{~h} \mathrm{(15} \mathrm{\textrm {min }}$ after switching to passive oxidation engine operating condition). The engine operating condition at $4.36 \mathrm{~h}$ is chosen to compare the model prediction accuracy at high temperature regions of the experiment. The inlet temperature to the MPF

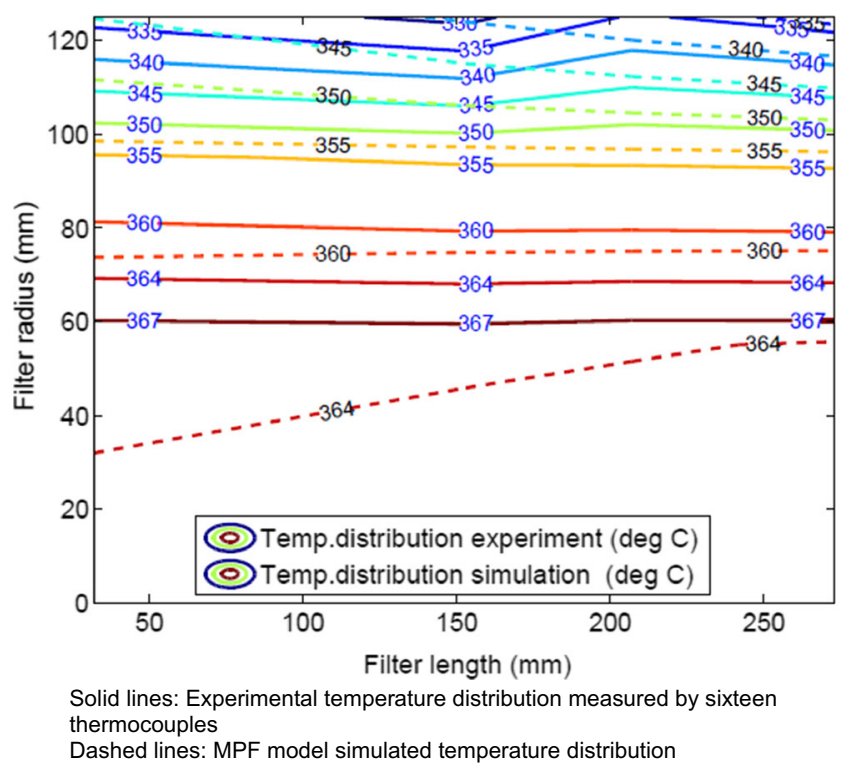

Fig. 12 Experimental (solid lines) and simulated (dashed lines) temperature distribution for PO-B10-15 experiment at $4.36 \mathrm{~h} \mathrm{(15} \mathrm{min}$ after switching to $\mathrm{PO}$ engine operating condition) model was simulated using Eq. (5), and the inlet mass flow rate fraction was simulated using volume ratio of the inlet channels in each zone while accounting for the average PM cake layer thickness at each zone as shown in Eq. (6). The detailed formulation of Eqs. 5 and 6 are documented in reference [1].

Temperature Factor $(\mathrm{x})=-2.493 \mathrm{x} 3+1.0585 \mathrm{x} 2-0.3285 \mathrm{x}$

$\dot{m}_{i, j}=\dot{m}_{\text {total }} \frac{V_{e s_{i, j}}}{\sum_{i} V_{e s_{i}}}$

where

$x \quad$ is the diameter ratio at a given location.

$\dot{m}_{i, j} \quad$ is the mass flow rate at each zone.

$V e s_{i, j}$ is the empty volume in each zone while accounting for the average PM cake layer thickness.

From Fig. 12, it is evident that the MPF model follows the experimental data. The maximum absolute temperature difference between the experimental and simulation data is $\cong 10^{\circ} \mathrm{C}$. From Fig. 12, the filter substrate temperatures for radiuses less than $80 \mathrm{~mm}$ are approximately constant. A slight increase (1$2{ }^{\circ} \mathrm{C}$ ) in axial temperature is due to the local PM oxidation. The substrate temperature close to the wall shows a slight decrease in temperature due to the dominant convection heat losses to the ambient compared to the local PM oxidation.

Figure 13 shows the comparison of average (arithmetic), minimum, and maximum filter substrate temperatures for the POB10-15 experiment along the axial direction at $4.36 \mathrm{~h} \mathrm{(15} \mathrm{min}$ after switching to the $\mathrm{PO}$ engine operating condition). The solid lines show the average filter substrate (arithmetic) temperature along the axial direction (calculated by averaging the substrate temperatures in all radial zones at a given axial length), and the dashed lines show the range of filter substrate temperature distribution (minimum and maximum substrate temperature along the radial direction) for a given axial section. The distance between two dashed lines (minimum and maximum) indicates how widely the temperature varies within the substrate along the radial direction. The spatial position of the average solid line relative to the dashed lines indicates the dominant temperatures in the CPF. The uniformity index of the temperature distribution $\left(U I_{T}\right)$ is calculated using the following formulae:

$U I_{T}=1-\frac{\sigma_{T}}{\mu_{T}}$

where

$\sigma_{T}$ is the standard deviation of filter substrate temperature over the entire filter.

$\mu_{T}$ is the average filter substrate temperature over the entire filter 
Fig. 13 Average (solid lines), minimum, and maximum (dashed lines) filter substrate temperatures comparison of experiment and simulation data for the PO-B1015 experiment at $4.36 \mathrm{~h}(15 \mathrm{~min}$ after switching to PO engine operating condition) along the axial direction

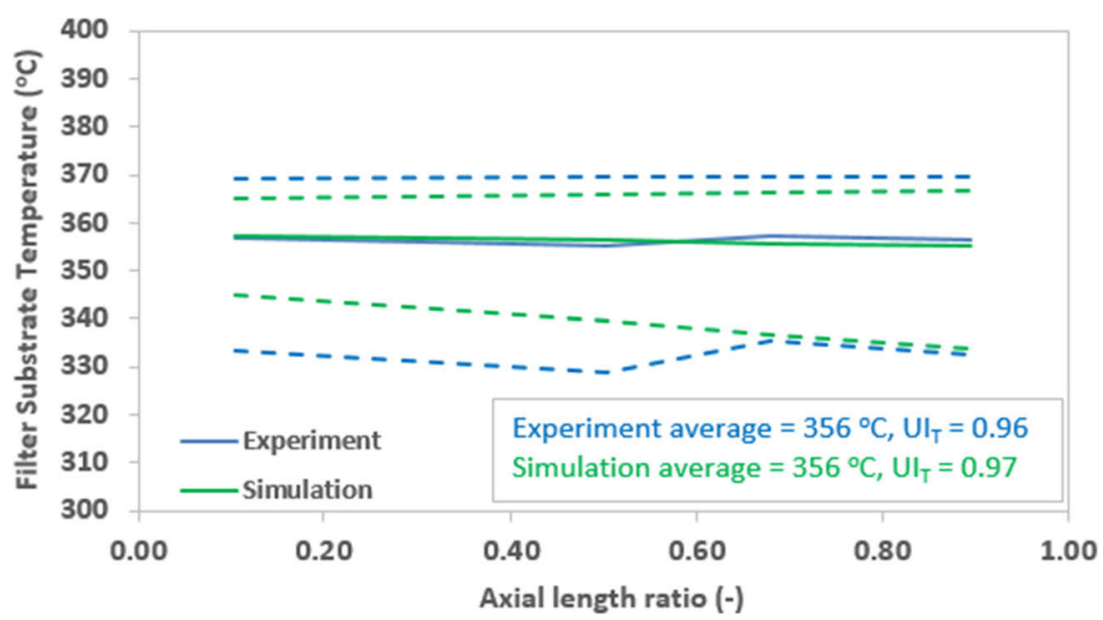

From Fig. 13, the average temperature along the axial direction is almost similar between experimental and simulation data (within $2{ }^{\circ} \mathrm{C}$ ). While comparing the average filter temperature over the entire filter (sum of all axial and radial zone temperatures), the MPF model simulation and experimental data are within $0.5{ }^{\circ} \mathrm{C}$. The $\mathrm{UI}_{\mathrm{T}}$ of the experimental data is 0.96 (meaning the standard deviation of the filter substrate temperature is $4 \%$ of the average substrate temperature) and the $\mathrm{UI}_{\mathrm{T}}$ of the simulation data is $0.97(1 \%$ higher than experimental data). Based on the above analysis, the $\mathrm{UI}_{\mathrm{T}}$ of the experimental and simulation data are similar and within $1 \%$ for the $\mathrm{PO}$ oxidation test conditions.

Figure 14 shows the comparison of average (arithmetic), minimum, and maximum overall reaction rates of the experimental and simulation data along the axial direction. The overall reaction rate was calculated using the following equation,

$R R_{o v}=\frac{S_{p} \rho Y_{i, j} O_{2} k_{O_{2}} W_{c}}{\alpha_{O_{2}} W_{O_{2}} \rho_{s}}+\frac{S_{p} \rho Y_{i, j N O_{2}} k_{N O_{2}} W_{c}}{\alpha_{N O_{2}} W_{N O_{2}} \rho_{s}}$

where $R_{\mathrm{ov}}$ is the overall reaction rate. Arrhenius reaction rates $\left(k_{\mathrm{O}_{2}}\right.$ and $\left.k_{\mathrm{NO}_{2}}\right)$ were calculated using Eqs. (3) and (4). The uniformity index of the overall reaction rate $\left(U I_{R R}\right)$ is calculated using the following formulae

$U I_{R R}=1-\frac{\sigma_{R R}}{\mu_{R R}}$

where

$\sigma_{R R}$ is the standard deviation of overall reaction rate of the entire filter.

$\mu_{R R}$ is the average overall reaction rate of the entire filter.

From Fig. 14, the overall reaction rate of the experimental and the simulation along the axial direction is within $8.2 \mathrm{E}-$ $06 \mathrm{~s}^{-1}(4.2 \%)$. The average reaction rate (average of all axial and radial reaction rates) of the simulation data is lower than the experimental data (simulation 1.91E-04 s ${ }^{-1}$ and experimental 1.94E-04 s $\mathrm{s}^{-1}$ ) attributing this to the lower filter substrate temperature in the simulation as shown in Fig. 13. The $\mathrm{UI}_{\mathrm{RR}}$ of the simulation is $13 \%$ higher than the experimental data (simulation $\mathrm{UI}_{\mathrm{RR}}$ is 0.80 and experimental $\mathrm{UI}_{\mathrm{RR}}$ is 0.73 ). The $\mathrm{UI}_{\mathrm{RR}}$ is much lower than the $\mathrm{UI}_{\mathrm{T}}$ ( simulation $\mathrm{UI}_{\mathrm{RR}}$ is 0.80
Fig. 14 Average (solid lines), minimum, and maximum (dashed lines) overall reaction rates comparison of the experiment and simulation data for the PO-B1015 experiment at $4.36 \mathrm{~h}(15 \mathrm{~min}$ after switching to $\mathrm{PO}$ engine operating condition) along the axial direction

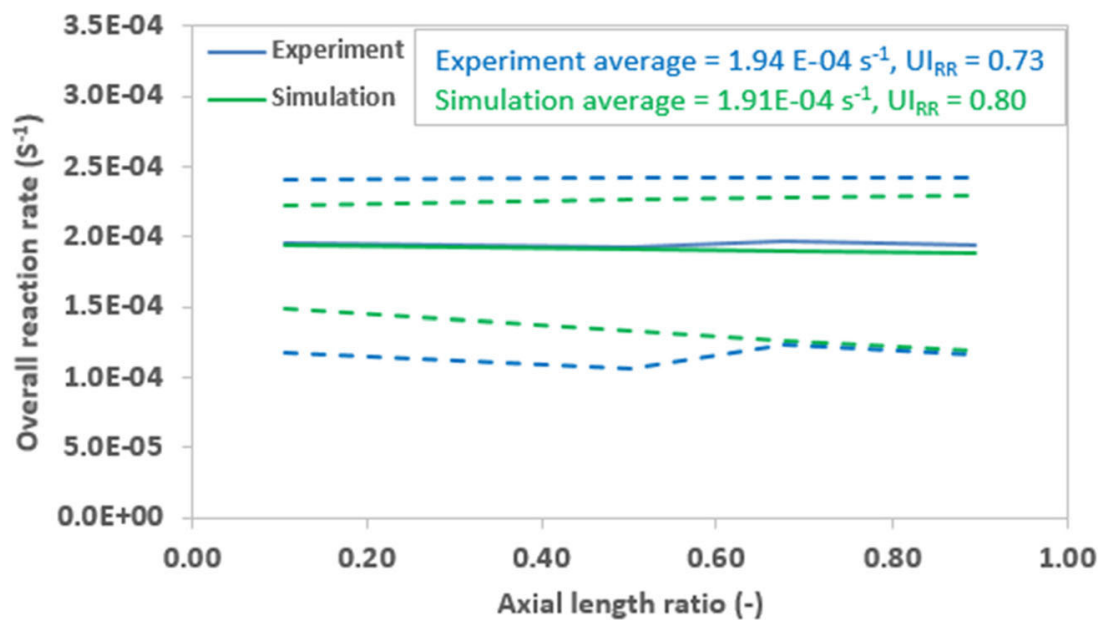


versus simulation $\mathrm{UI}_{\mathrm{T}}$ is 0.97 ) indicating a $3 \%$ change in $\mathrm{UI}_{\mathrm{T}}$ causes $20 \%$ change in $\mathrm{UI}_{\mathrm{RR}}$, which results in non-uniform distribution of PM oxidation and distribution within the filter substrate. This is mainly because the PM oxidation rate in the Arrhenius reaction rate equations (Eqs. 3 and 4) have an exponential relationship with the filter substrate temperature.

\subsection{PM Mass Retained}

Figure 15 shows the cumulative PM mass retained in the filter in comparison with the cumulative inlet PM mass and PM oxidation masses. $\mathrm{NO}_{2}$ assisted PM oxidation is the dominant mode of PM oxidation shown by the dashed line because of the $\mathrm{NO}_{2}$ concentration $(101 \mathrm{ppm})$. The thermal $\left(\mathrm{O}_{2}\right)$ assisted PM oxidation is low $(<0.3 \mathrm{~g})$ compared to $\mathrm{NO}_{2}$ assisted PM oxidation due to the lower exhaust gas temperature during the PM oxidation $\left(355^{\circ} \mathrm{C}\right)$. From Fig. 15 , the MPF model simulated the PM mass retained within the filter substrate with the maximum absolute error of $2.3 \mathrm{~g}$ between the experimental and the simulated PM mass retained at the end of the stage 3 loading phase of the experiment.

Figures 16 and 17 show the PM mass loading distribution at the start and end of PM oxidation by passive oxidation. From Figs. 16 and 17, the PM loading is almost uniform $(2.3 \pm 0.04 \mathrm{~g} / \mathrm{L})$ at the beginning of oxidation, whereas the PM loading distribution significantly varies at the end of passive oxidation. The minimum PM mass loading is $0.91 \mathrm{~g} / \mathrm{L}$ and increases to a maximum value of $1.9 \mathrm{~g} / \mathrm{L}$ at the outer radius of the filter substrate. This is mainly due to the lower exhaust gas temperature at the outer radius of the filter due to the ambient convective and radiative heat transfer compared to the center of the filter substrate.

Figure 18 shows the simulated PM mass loading distribution along the axial and radial direction at the end of post-

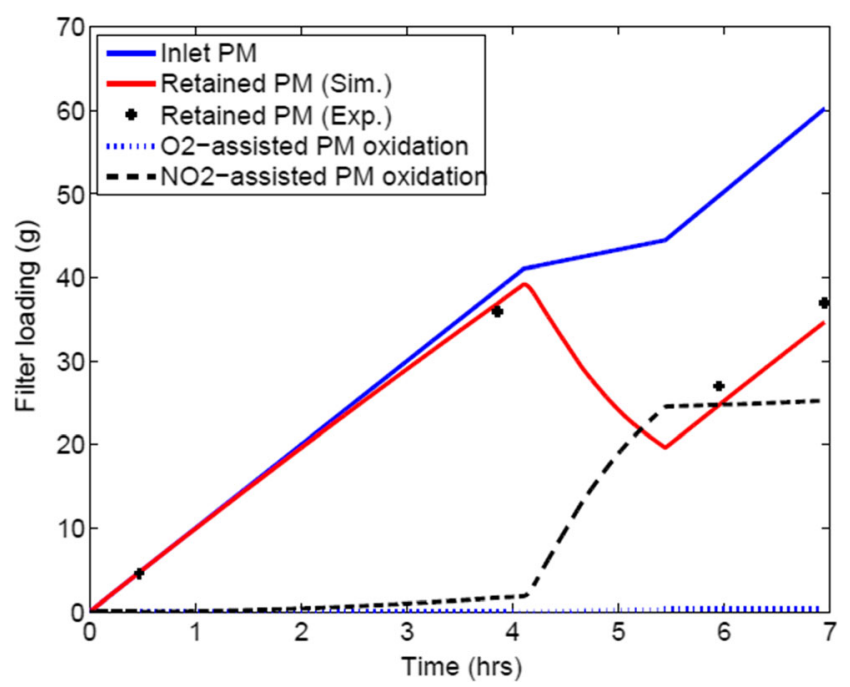

Fig. 15 Comparison of PM mass retained in the experimental data and simulation model along with the model cumulative for PM inlet and oxidation masses for the PO-B10-15 experiment

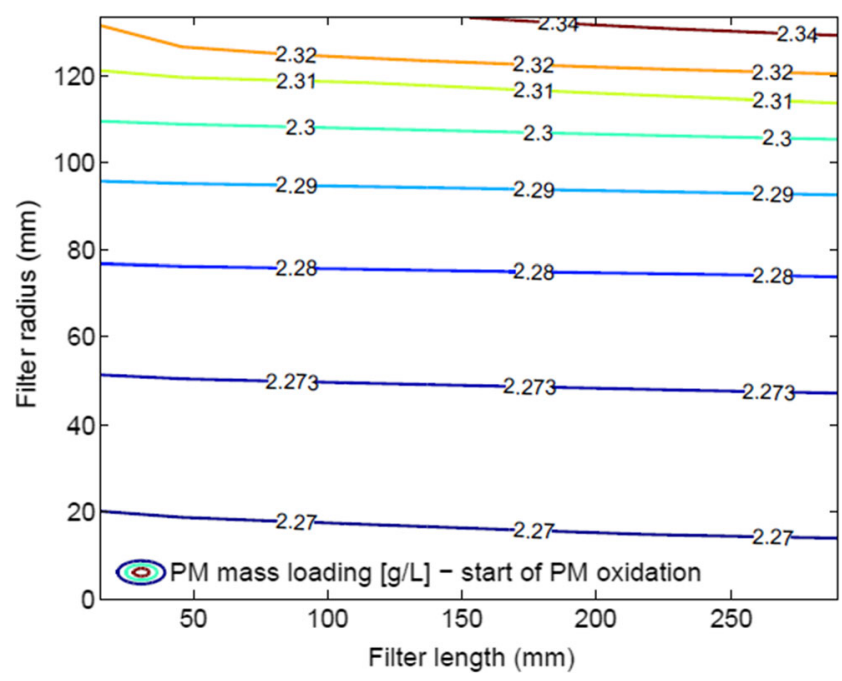

Fig. 16 Simulated PM mass loading distribution along axial and radial directions at $4.11 \mathrm{~h}$-start of passive oxidation for the PO-B10-15 experiment

loading for the PO-B10-15 experiment. From Fig. 18, the PM loading distribution at the end of post-loading is also non-uniform (1.78 to $2.5 \mathrm{~g} / \mathrm{L})$. Comparing Fig. 18 with Fig 17, the non-uniform PM loading originated during PM oxidation by passive oxidation due to the temperature gradient within the filter and the non-uniform PM loading continued further during the post-loading phase of the experiment.

Figure 19 shows the axial and radial distribution of PM loading measured by Foley [17] for the same engine in this study for the passive oxidation case (average $\mathrm{CPF}$ temperature $348^{\circ} \mathrm{C}, \mathrm{NO}_{2}$ concentration of $196 \mathrm{ppm}$, and ULSD fuel type) with the end of passive oxidation PM mass loading of 3.25 g/L. Comparing Figs. 19 and 17, the simulation model data shows the uniform filter loading along the length the filter

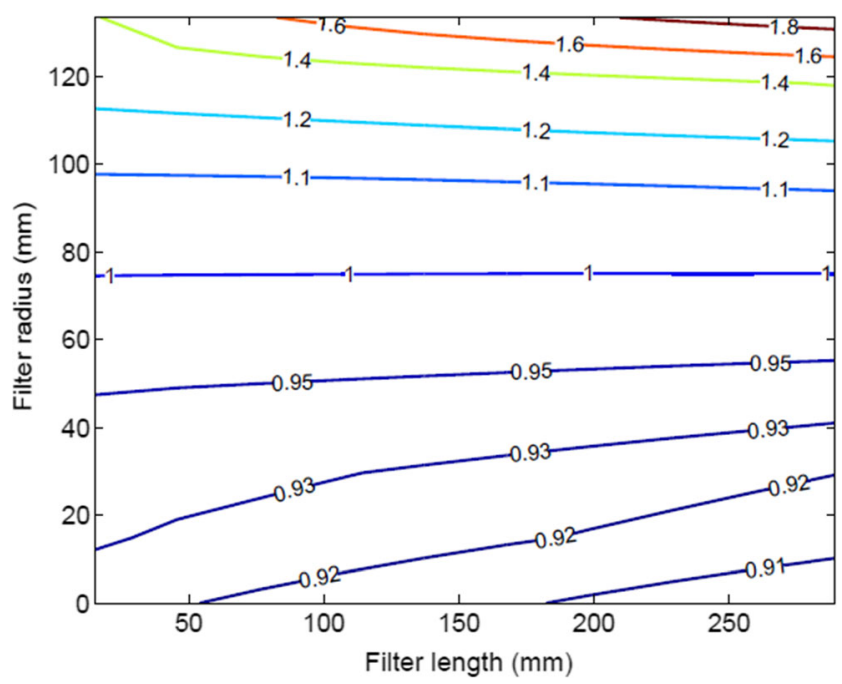

Fig. 17 Simulated PM mass loading distribution along axial and radial directions at $5.46 \mathrm{~h}$ - end of passive oxidation for the PO-B10-15 experiment 


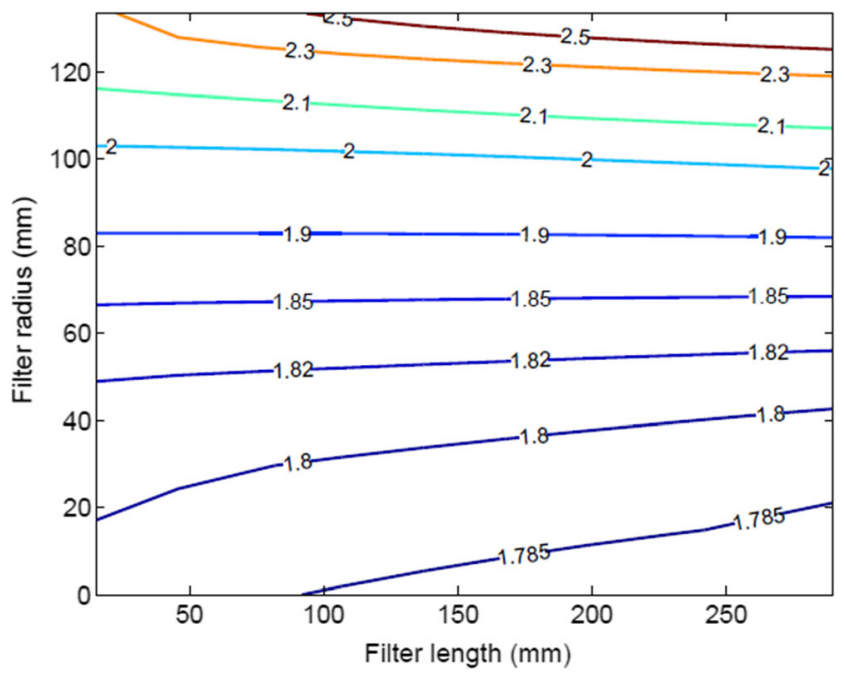

Fig. 18 Simulated PM mass loading distribution along axial and radial directions at $6.95 \mathrm{~h}$ - end of post-loading for the PO-B10-15 experiment

whereas the experimental data in Fig. 19 shows the uniform PM loading up to axial length ratios of 0.7 (filter length $<215 \mathrm{~mm}$ ). For axial length ratios $>0.7$ (filter length $>215 \mathrm{~mm}$ ), the experimental data shows an increase in PM loading close to the outlet end of the substrate (axial length ratios $>0.7$ or filter length $>215 \mathrm{~mm}$ ). This may be explained by PM cake and ash particle transport mechanisms (regeneration-induced and flow-induced) proposed by Sappok et al. [23] using the optically accessible filter core sample in a catalyst bench reactor. During passive oxidation of PM, the particle in contact with washcoat oxidizes the PM cake and reduces the adhesive force [23] which aids in particle detachment and transports towards the plugged end of the filter substrate. This particle transport mechanism is not included in the MPF model. The PM loading experimental data close to the inlet (axial length ratios $<0.05$ ) and outlet sections (axial length ratio $>0.97$ ) are considered to be less accurate due to the error associated with the scanning procedure and PM loading analysis methodology around the channel plugs [17]. The radial distribution of PM loading with the experimental data shows a slight reduction in radially outward (subplot 19ddiameter of 231-267 mm) direction. This may be due to the uncertainties associated with the terahertz analyzer ability to scan at the outer surfaces [17]. Both the simulation model and experimental data show relatively uniform PM loading radially from the $80 \mathrm{~mm}$ radius to the centerline of the filter. This is consistent with uniform temperature trends observed from the experimental data and the MPF model results.

Figure 20 shows the comparison of average, minimum, and maximum PM mass loading distribution at the start and end of the PM oxidation for PO-B10-15 experiment. The solid lines show the average PM mass loading along the axial direction (calculated by averaging the PM loading in all radial zones at a given axial length) and the dotted lines show the range of PM loading distribution (minimum and maximum PM loading along the radial direction) for a given axial section. The

a) Radial Section 1- Diameter of $0-133 \mathrm{~mm}$

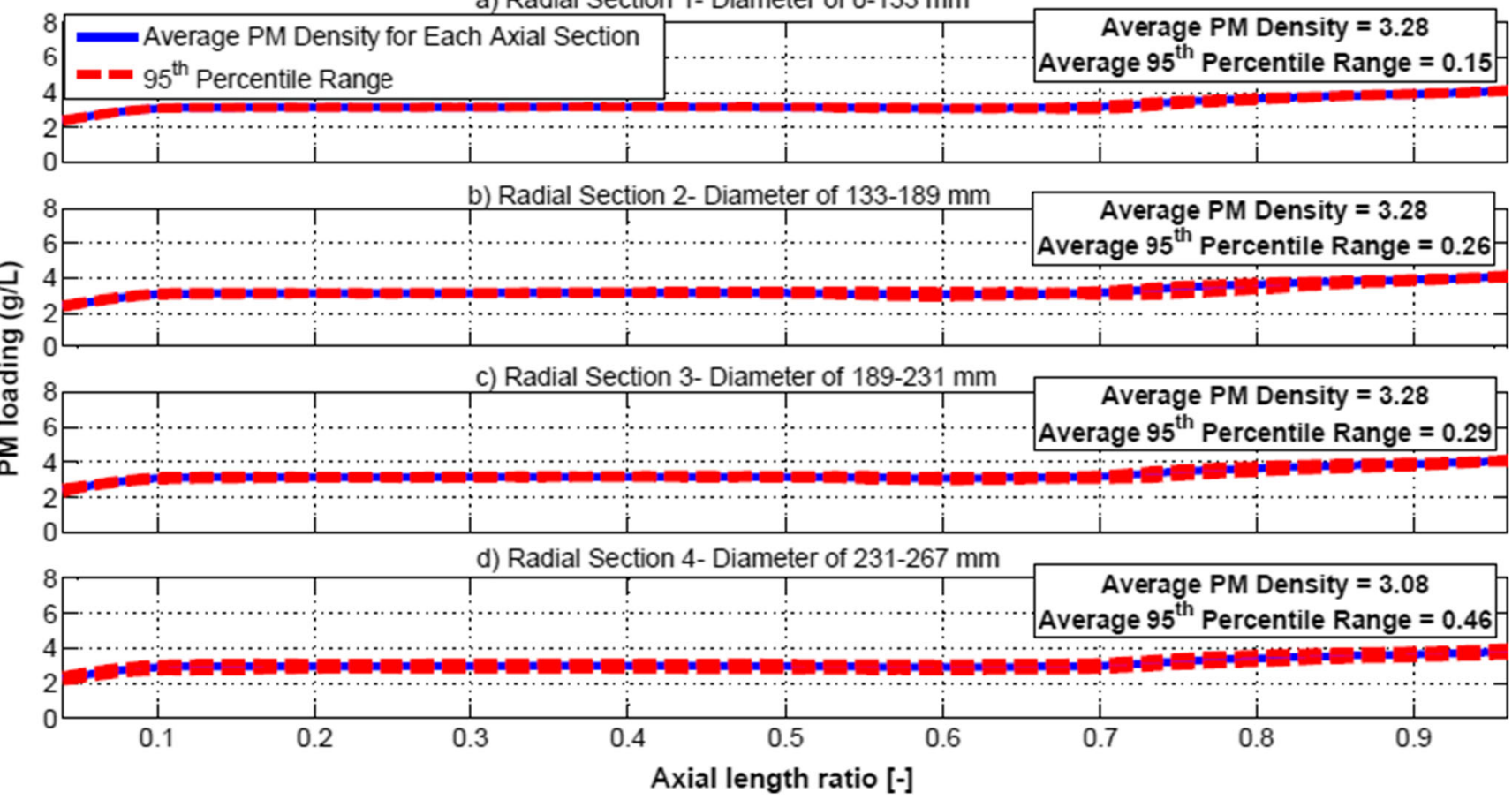

Fig. 19 Test 8 end of passive oxidation $(P O)$ phase axial and radial PM distribution measured — adapted from reference [7] for 2007 ISL engine, axial length ratio of 1.0 corresponds to $305 \mathrm{~mm}$ filter length, axial uniformity index for plots $a-d$ are 0.91 , average radial uniformity index $=0.97$, and average angular uniformity index $=0.98$ 

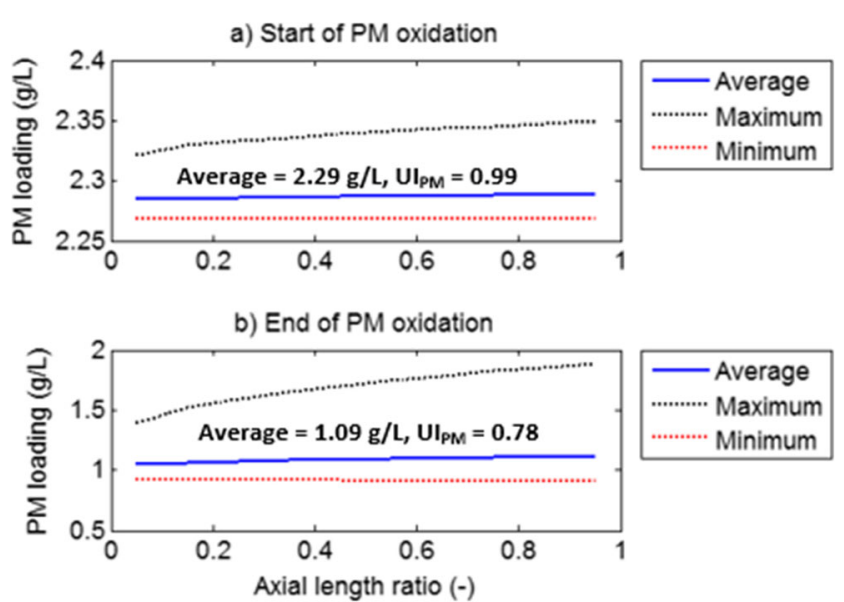

Fig. 20 Comparison of average (solid lines), minimum, and maximum (dotted lines) simulated PM mass loading distribution for the PO-B10-15 experiment - a start of PM oxidation ( $4.11 \mathrm{~h})$ and $\mathbf{b}$ at the end of the PM oxidation $(5.46 \mathrm{~h})$

uniformity index of the filter loading distribution $\left(U I_{P M}\right)$ is calculated using the following formulae:

$U I_{P M}=1-\frac{\sigma_{P M}}{\mu_{P M}}$

where

$\sigma_{P M}$ is the standard deviation of PM mass loading over the entire filter.

$\mu_{P M}$ is the average PM mass loading over the entire filter.

From Fig. 20, the average simulated PM mass loading distribution at the start of PM oxidation by passive oxidation is uniform along the axial direction (within $2.29 \pm 0.01 \mathrm{~g} / \mathrm{L}$ ). The minimum and maximum filter loading within each axial section (radial variation) is small (within 2.27 to $2.35 \mathrm{~g} / \mathrm{L}$ ). Hence, the $\mathrm{UI}_{\mathrm{PM}}$ is 0.99 , indicating uniform PM loading distribution within the filter. The simulated average PM mass loading at the end of PM oxidation by passive oxidation is $1.09 \mathrm{~g} / \mathrm{L}$ and a small increase ( 1.05 to $1.12 \mathrm{~g} / \mathrm{L}$ ) in average PM mass loading axially towards the end of the filter. The minimum and maximum filter loading distribution (radial distribution) within each axial section is also increased $(0.90$ to $1.89 \mathrm{~g} /$ $\mathrm{L})$ as shown by the dotted lines. Hence, the $\mathrm{UI}_{\mathrm{PM}}$ at the end of $\mathrm{PM}$ oxidation is reduced to 0.78 , indicating non-uniform distribution of PM loading within the filter, mainly caused by the non-uniform temperature and reaction rate distribution during the PM oxidation as shown in Figs. 12, 13, and 14.

Comparing the PM distribution trends of Fig. 20b with Fig. 19, the simulation data in Fig. 20b shows the uniform PM loading along the axial direction $(1.05$ to $1.12 \mathrm{~g} / \mathrm{L})$ and experimental data in Fig. 19 also show a uniform loading of 3 to $3.1 \mathrm{~g} / \mathrm{L}$ (arithmetic average of radial sections 1 to 4 ) for axial length of ratios $>0.1$ and $<0.7$. The PM loading differences in other sections (for axial length ratios $<0.05$ and $>0.7$ ) were discussed in earlier paragraphs. Both the simulation model and experimental data shows spatial distribution of PM loading. The spatial variation of filter loading distribution in simulation (Fig. 20b) is 0.92 to $1.89 \mathrm{~g} / \mathrm{L}$, and the experimental data (Fig. 19) is 2.8 to $3.3 \mathrm{~g} / \mathrm{L}$ (for an axial length ratios of 0.1 to 0.7). One of the reasons for the smaller spatial distribution of experimental data is that the distribution is based on $95 \%$ percentile (difference between 97.5 and 2.5 percentiles) loading values whereas the simulation data is based on absolute minimum and maximum ( 0 and $100 \%$ ) values at each axial location.

Figure 21 shows the average, minimum, and maximum simulated PM mass loading distribution at the end of postloading (end of stage 4) for the PO-B10-15 experiment. From Fig. 21, the average PM loading is increased to $1.96 \mathrm{~g} /$ $\mathrm{L}$ (from $1.09 \mathrm{~g} / \mathrm{L}$ at the end of PM oxidation) and the $\mathrm{UI}_{\mathrm{PM}}$ is improved to 0.87 (from $\mathrm{UI}_{\mathrm{PM}}$ of 0.78 at the end of PM oxidation) at the end of post-loading. Comparing Fig. 21 with Fig.20b, the gap between the dashed lines in Fig. 21 and dotted lines in Fig.20b is similar (within $0.01 \mathrm{~g} / \mathrm{L}$ ), indicating that the non-uniform distribution caused by PM oxidation remained in
Fig. 21 Comparison of average (solid lines), minimum, and maximum (dashed lines) simulated PM mass loading distribution at the end of postloading $(6.95 \mathrm{~h})$ for the PO-B1015 experiment

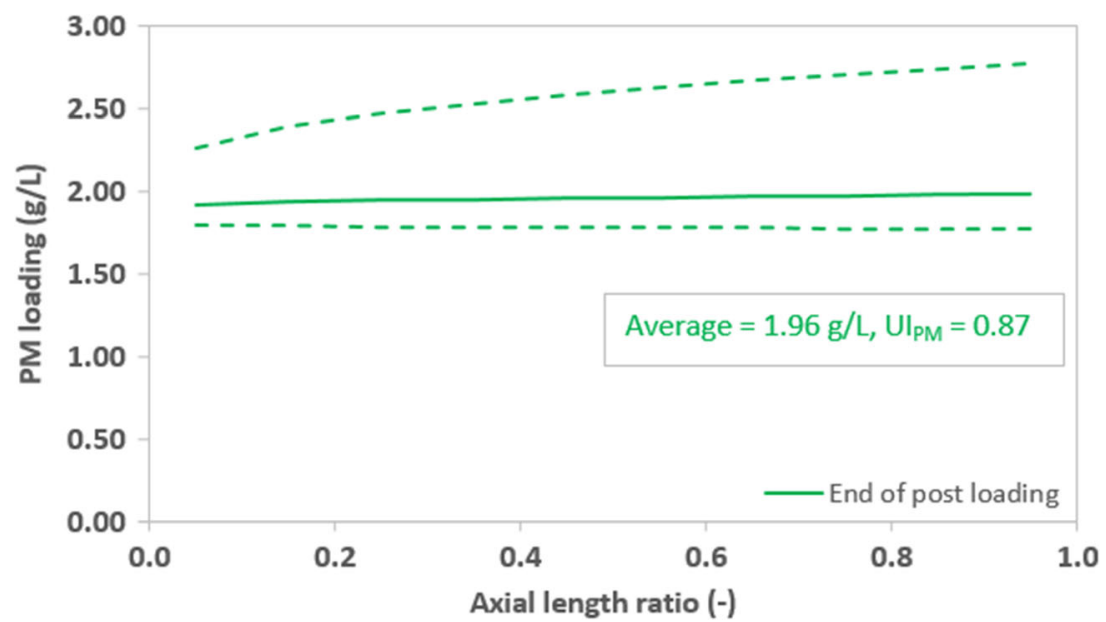


the post-loading phase. However, the uniformity index is improved at the end of post-loading due to the increase in average PM loading for a similar level of PM loading distribution (standard deviation of PM mass loading at end of PM oxidation is $0.24 \mathrm{~g} / \mathrm{L}$ and at the end of post-loading is $0.25 \mathrm{~g} / \mathrm{L}$ ).

Figure 22 shows the PM cake layer thickness variation along the radial direction simulated by the MPF model. From Fig. 22, PM cake layer thickness varies significantly in the radial direction during the passive oxidation phase of the experiment. The varying cake layer thickness is observed until the end of the post-loading phase of the experiment. At the end of post-loading, the PM cake layer thickness at the center of the filter $(R=$ $0 \mathrm{~mm}$ ) was $19 \mu \mathrm{m}$ whereas the PM cake layer thickness was $24 \mu \mathrm{m}$ at the outer radius of the filter $(R=133.5 \mathrm{~mm})$.

Figures 23 and 24 show the PM cake layer thickness variation along the axial direction for the center zone $(R=0 \mathrm{~mm})$ and outer most zone $(R=133.5 \mathrm{~mm})$ of the filter substrate. From Figs. 23 and 24, PM cake layer thickness is axially uniform during the loading phase of the experiment (from 0 to $3.87 \mathrm{~h}$ ) whereas from the beginning of post-loading $(5.46 \mathrm{~h})$ to the end of post-loading ( $6.9 \mathrm{~h})$, the PM cake layer thickness varies nonuniformly as shown in Fig. 24. At the end of post-loading $(6.9 \mathrm{~h})$, the minimum cake layer thickness is $23.8 \mu \mathrm{m}$ at the inlet of the filter $(\mathrm{x} / \mathrm{L}=0)$ and maximum cake layer thickness is $29.2 \mu \mathrm{m}$ at the outlet of the filter substrate $(\mathrm{x} / \mathrm{L}=1.0)$. The increase in PM cake layer thickness towards the end of the filter $(\mathrm{x} / \mathrm{L}=1.0)$ is mainly because of lack of PM oxidation in the radially outward direction due to the lower substrate temperature compared to the center zone of the filter.

\subsection{Active Regeneration Results}

The active regeneration experimental data used for the model calibration are listed in Table 7 in Appendix 1. The filter

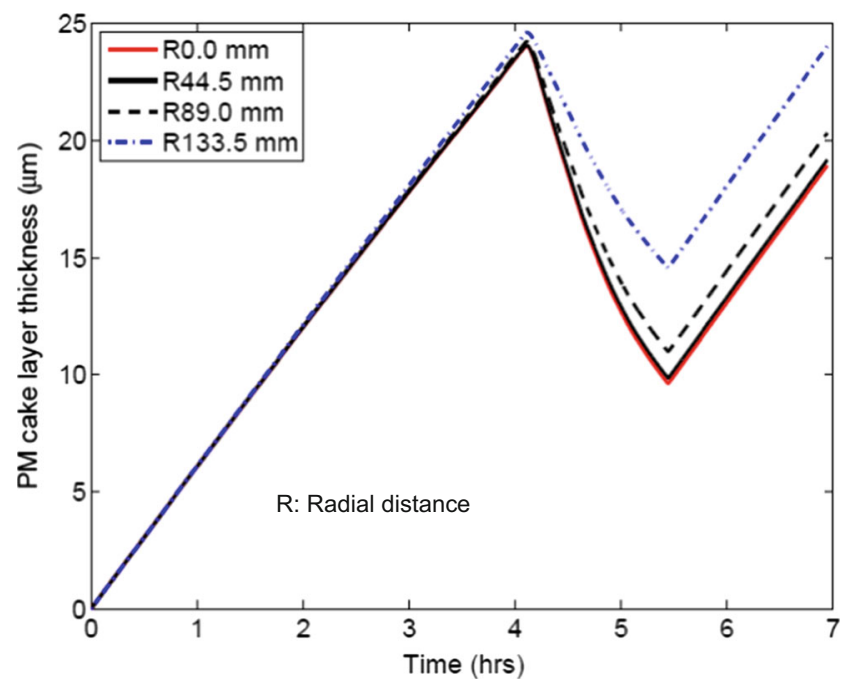

Fig. 22 Simulated PM cake layer thickness variation along radial direction at the filter substrate inlet (15.2 $\mathrm{mm}$ from inlet axial direction) for the PO-B10-15 experiment

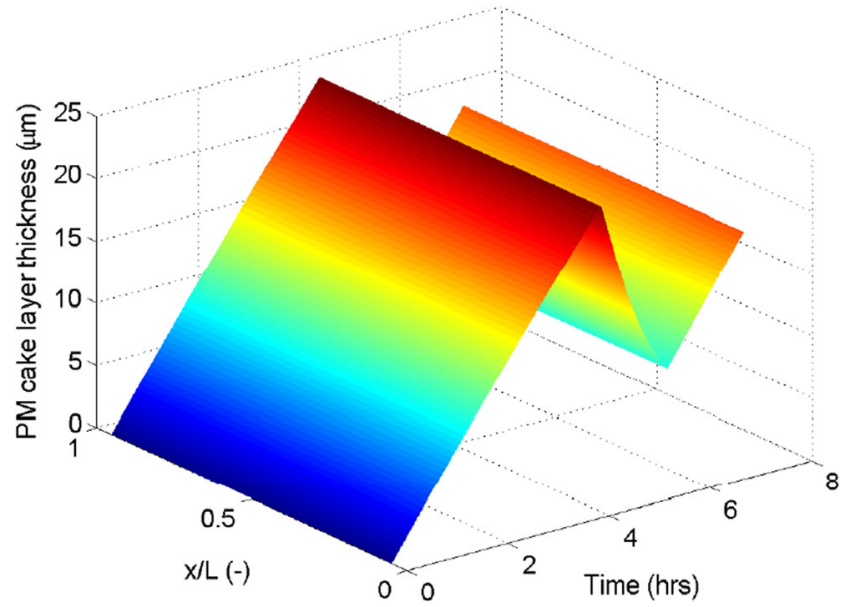

Fig. 23 Simulated PM cake layer thickness distribution along axial directions for the entire test duration at the center zone of the filter $(R=$ $0 \mathrm{~mm}$ ) for the PO-B10-15 experiment

substrate temperatures during active regeneration experiments are in the range of $450-600^{\circ} \mathrm{C}$ which is higher than the passive oxidation experiments explained in the previous section. The active regeneration experiments are short in duration (6 to 39 min) because of the high PM oxidation rates. The PM oxidation during active regeneration is governed by thermal $\left(\mathrm{O}_{2}\right)$ assisted PM oxidation mechanism. Considering the higher filter substrate temperature and short PM oxidation duration and its effect on the heat transfer, temperature, and filter loading distribution within the filter, the MPF model validation was also carried out on one sample active regeneration experiment (AR-B10-1). The results are presented in the following section.

\subsection{Temperature Distribution}

Figure 25 shows the radial temperature distribution of the ARB10-1 experiment as measured by $\mathrm{C} 1-\mathrm{C} 4$ thermocouples and temperatures simulated by the MPF model at the inlet of the

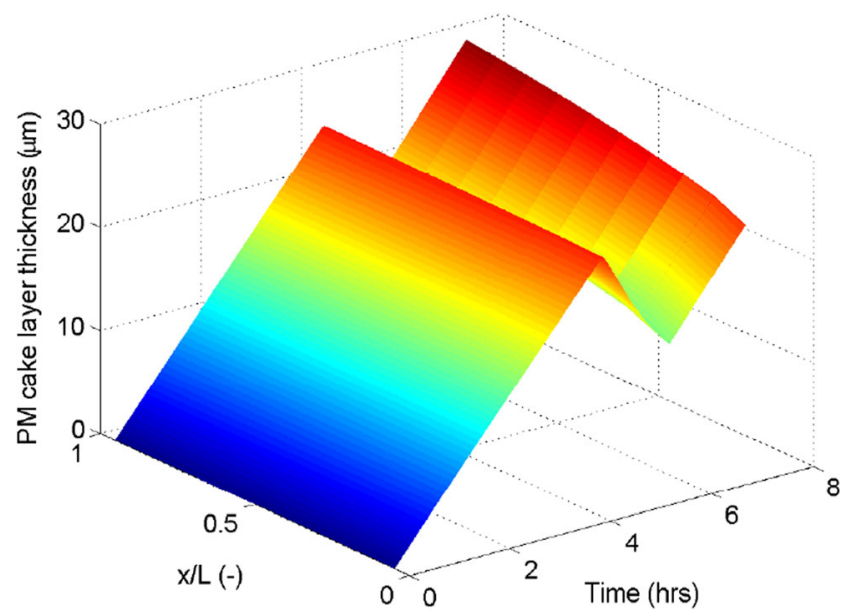

Fig. 24 Simulated PM cake layer thickness distribution along the axial direction for the entire test duration at the outer most zone of the filter $(R=$ $133.5 \mathrm{~mm}$ ) for the PO-B10-15 experiment 


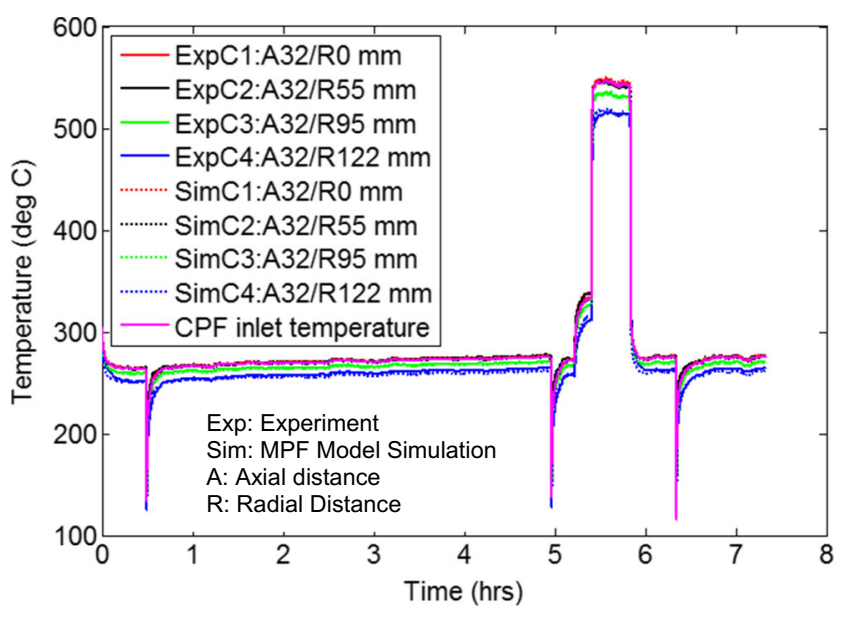

Solid lines: Experimental temperature distribution measured by sixteen thermocouples

Dashed lines: MPF model simulated temperature distribution

Fig. 25 Radial temperature distribution at filter inlet for AR-B10-1 experiment

filter. The inlet flow and temperature distribution to the model were simulated using Eqs. 5 and 6 shown in the earlier section.

As shown in Fig. 25, the temperature distribution simulated by the MPF model is within $\left(12{ }^{\circ} \mathrm{C}\right)$ of the experimental data (excluding the temperature spikes related to the experimental procedure and transition phase of moving in and out of the AR phase of the experiment). Active regeneration experiment ARB10-1 also shows significant temperature $\operatorname{drop}\left(\cong 40^{\circ} \mathrm{C}\right)$ close to the outer surface of the filter substrate $(R=122 \mathrm{~mm})$ during the active regeneration phase of the experiment (15 min after the fuel dosing begins).

Figure 26 shows the experimental (solid lines) and simulated temperature (dashed lines) distribution for the AR-B10-1 experiment at $5.63 \mathrm{~h} \mathrm{(15} \mathrm{min} \mathrm{after} \mathrm{start} \mathrm{of} \mathrm{fuel} \mathrm{dosing).} \mathrm{From}$

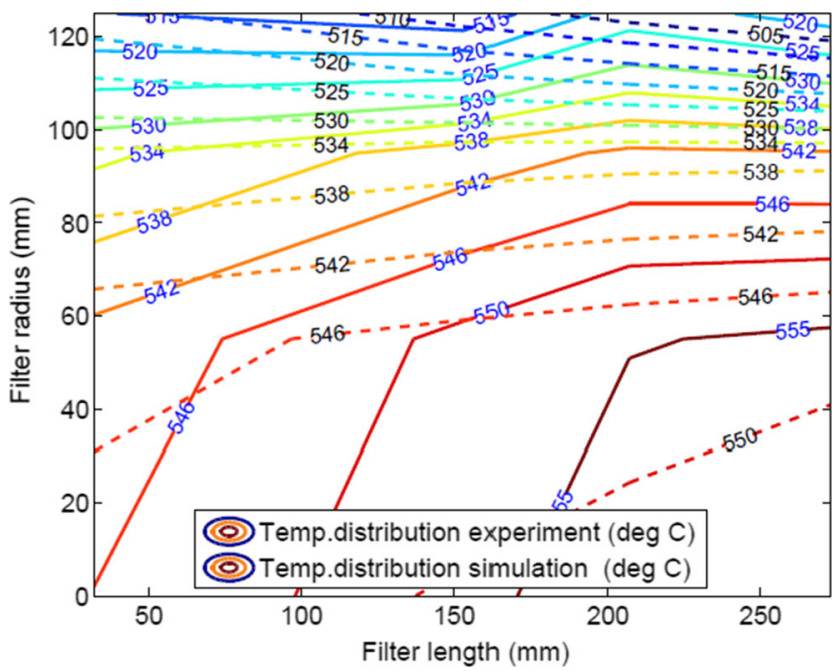

Solid lines: Experimental temperature distribution measured by sixteen thermocouples

Dashed lines: MPF model simulated temperature distribution

Fig. 26 Temperature distribution for the AR-B10-1 experiment at $5.63 \mathrm{~h}$ (15 min after start of fuel dosing)
Fig. 26, the experimental filter substrate temperature shows an increase in temperature $\left(10-12{ }^{\circ} \mathrm{C}\right.$ at filter radius below $40 \mathrm{~mm}$ ) axially due to the local PM oxidation. The substrate temperature close to the wall shows a lower increase in temperature axially $\left(5{ }^{\circ} \mathrm{C}\right.$ approximately) due to the dominant convection and radiative heat loss to the ambient compared to the local PM oxidation. The MPF simulation model also shows an increase in temperature $\left(5^{\circ} \mathrm{C}\right)$ in the axial direction due to PM oxidation; however, the magnitude of increase is low compared to the experimental data. The model in reference [1] assumed constant temperature at radius $r=0$. In this manuscript, the boundary condition assumption was revised to zero gradient to be consistent with symmetry boundary conventions. The temperature differences between two boundary conditions (constant temperature versus zero gradient boundary) are $\cong 4{ }^{\circ} \mathrm{C}$ at radius $=0$. This difference is even smaller $\left(<1{ }^{\circ} \mathrm{C}\right)$ for the passive oxidation cases. However, the passive oxidation (PO-B10-15) and active regeneration plots (AR-B10-1) results were updated with the new results. The maximum error observed in simulation of PM retained is less than $0.1 \mathrm{~g}$ with zero-gradient boundary compared with constant temperature boundary condition. However, the model simulation results for PM mass retained were also updated with zero gradient boundary condition for all 18 experiments (Table 9).

Figure 27 shows the average filter substrate temperature (arithmetic average of all the temperature data) comparison of the experimental and simulation data. The $\mathrm{UI}_{\mathrm{T}}$ for the filter was calculated using Eq. (7). From Fig. 27, the average temperature of the MPF model simulation is $5{ }^{\circ} \mathrm{C}$ lower than the experimental data. The minimum filter substrate temperature of the simulation is lower than the experimental data by $20^{\circ} \mathrm{C}$ towards the end of the filter (axial length ratio $=0.90$ ). The $\mathrm{UI}_{\mathrm{T}}$ of the MPF model simulation was the same as the experimental data (simulation and experimental $\mathrm{UI}_{\mathrm{T}}=0.97$ ), indicating a

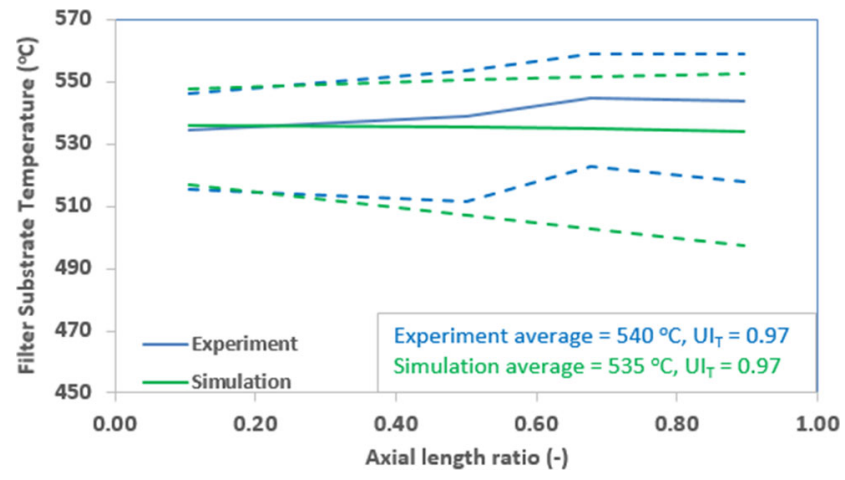

Dashed lines: Minimum and maximum filter substrate temperature of experimental and simulation data

Fig. 27 Average (solid lines), minimum, and maximum (dashed lines) filter substrate temperatures comparison of experiment and simulation data for the AR-B10-1 experiment at $5.63 \mathrm{~h} \mathrm{(15} \mathrm{min} \mathrm{after} \mathrm{switching} \mathrm{to}$ AR engine operating condition) 
similar temperature distribution (standard deviation of filter substrate temperature is the same) within the filter in the simulation and experimental data. The differences in the shape of the temperature curves for axial length ratios $>0.5$ is mainly due to the increase in axial temperature $\left(\cong 10^{\circ} \mathrm{C}\right.$ in average temperature and $\cong 20^{\circ} \mathrm{C}$ close to outer radiuses) in the experimental data. This axial temperature increase is not captured very well in the simulation, especially close to the outer radiuses (the temperature differences between simulation and experimental data are $<8^{\circ} \mathrm{C}$ at $r=0$ ).

Figure 28 shows the average (arithmetic average of all reaction rates), minimum, and maximum overall reaction rates comparison of the experimental and simulation data. The overall reaction rate was calculated using Eq. (8). The uniformity index of the reaction rate was calculated using Eq. (9). The overall reaction rate of the simulation data is lower than the experimental data (simulation: $1.45 \mathrm{E}-03 \mathrm{~s} \mathrm{~s}^{-1}$, experimental: $1.65 \mathrm{E}-03 \mathrm{~s}^{-1}$ ) due to lower filter substrate temperature in simulation data $\left(6{ }^{\circ} \mathrm{C}\right.$ from Fig. 27) compared to the experimental data. The $\mathrm{UI}_{\mathrm{RR}}$ of the simulation and experimental data are similar (simulation $\mathrm{UI}_{\mathrm{RR}}$ is 0.61 and experimental $\mathrm{UI}_{\mathrm{RR}}$ is 0.63). It is important to note that the $\mathrm{UI}_{\mathrm{RR}}$ is much lower than the $\mathrm{UI}_{\mathrm{T}}\left(\mathrm{UI}_{\mathrm{RR}}\right.$ is 0.63 versus $\mathrm{UI}_{\mathrm{T}}$ of 0.97$)$, indicating that a $3 \%$ change in the $\mathrm{UI}_{\mathrm{T}}$ causes a $37 \%$ change in $\mathrm{UI}_{\mathrm{RR}}$ due to the exponential relationship of temperature in the Arrhenius reaction rate equation. This results in non-uniform PM oxidation and distribution within the filter substrate. Comparing with the PO reaction rates in Fig. 14, the AR overall reaction rate is 7.5 to 8.5 times higher than the $\mathrm{PO}$ reaction rate (simulation overall reaction rate for AR test condition: $1.45 \mathrm{E}-03 \mathrm{~s}^{-1}$, simulation overall reaction rate for PO test condition: $1.91 \mathrm{E}-04 \mathrm{~s}^{-1}$ ). This indicates that for similar $\mathrm{UI}_{\mathrm{T}}$ between $\mathrm{PO}$ and $\mathrm{AR}$ test conditions $\left(\mathrm{PO}\right.$ simulation $\mathrm{UI}_{\mathrm{T}}=0.97, \mathrm{AR}$ simulation $\mathrm{UI}_{\mathrm{T}}=$ 0.97), the AR test conditions cause more non-uniform $P M$ oxidation and distribution than the PO test conditions.

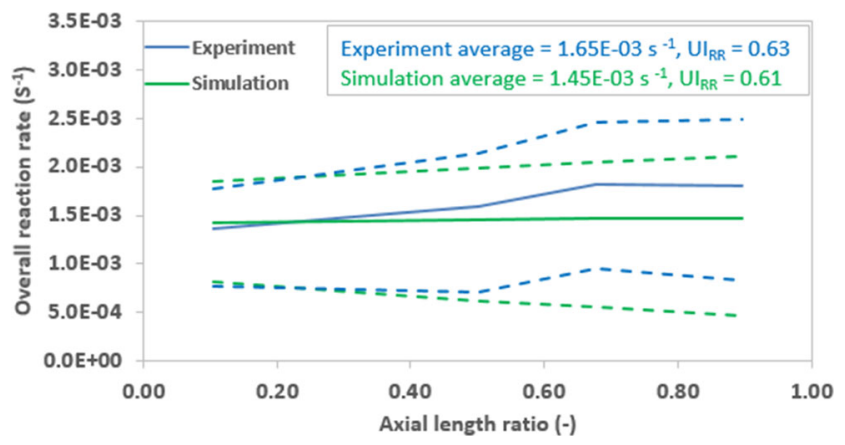

Dashed lines: Minimum and maximum overall reaction rates of experimental and simulation data

Fig. 28 Average (solid lines), minimum, and maximum (dashed lines) overall reaction rate comparison of the experiment and simulation data for the AR-B10-1 experiment at $5.63 \mathrm{~h}$ (15 min after switching to AR engine operating condition)

\subsection{PM Mass Retained}

Figure 29 shows the cumulative PM mass retained in the filter in comparison with the cumulative inlet PM and PM oxidation masses. From Fig. 29, thermal $\left(\mathrm{O}_{2}\right)$ assisted PM oxidation is the dominant mode of PM oxidation shown by the dotted line because of the increased reaction rate due to the higher exhaust gas temperature $\left(530^{\circ} \mathrm{C}\right)$ and $\mathrm{O}_{2}$ concentration $(7.8 \%)$. The overall PM oxidized (at the end of post-loading at $7.33 \mathrm{~h}$ ) by thermal $\left(\mathrm{O}_{2}\right)$ assisted PM oxidation is $82 \%$ whereas the $\mathrm{NO}_{2}$ assisted $\mathrm{PM}$ oxidation is $18 \%$ due to the lower $\mathrm{NO}_{2}$ concentration in the exhaust gas. The MPF model simulated the PM mass retained in the filter substrate and the maximum absolute error between experiment and the simulation is $2.8 \mathrm{~g}$ at the end of stage 2 loading condition.

Figures 30 and 31 show the PM mass loading distribution at the start and at the end of the PM oxidation during the AR phase of the experiment. Figure 32 shows the PM mass loading distribution at the end of post-loading. From Figs. 30 and 31 , the PM loading is almost uniform at the beginning of the active regeneration experiment $(<0.14 \mathrm{~g} / \mathrm{L}$ variation in $\mathrm{PM}$ loading across entire filter) whereas at the end of active regeneration, the PM loading distribution varies significantly. The minimum PM mass loading is $0.4 \mathrm{~g} / \mathrm{L}$ up to a filter radius of $80 \mathrm{~mm}$ and increases to a maximum value of $2.6 \mathrm{~g} / \mathrm{L}$ at the outer radius of the filter substrate. This is mainly due to the lower exhaust gas temperature at the outer radius of the filter due to the ambient convective and radiative heat loss compared to the center of the filter substrate. Comparing with passive oxidation PM loading shown in Fig. 17, the filter loading distribution varies significantly (from 0.2 to $2.4 \mathrm{~g} / \mathrm{L}$ ) for active regeneration experiments, which is attributed to the large temperature gradient associated with the active regeneration experiments. From Fig. 32, the PM loading increases (by 0.8 to $0.9 \mathrm{~g} / \mathrm{L}$ ) at the end of post-loading compared to the end

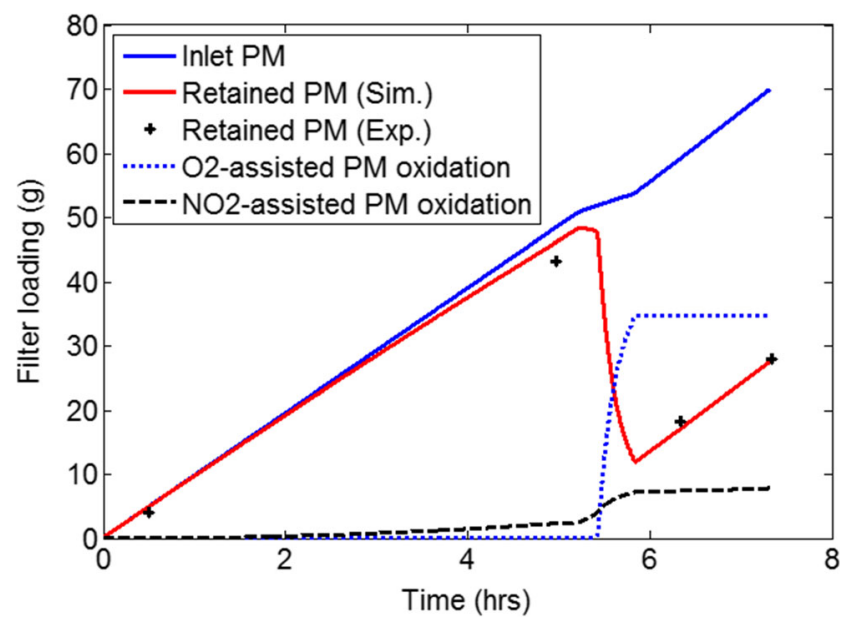

Fig. 29 Comparison of PM mass retained in the experimental data and simulation model along with the cumulative PM inlet and oxidation masses for the AR-B10-1 experiment 


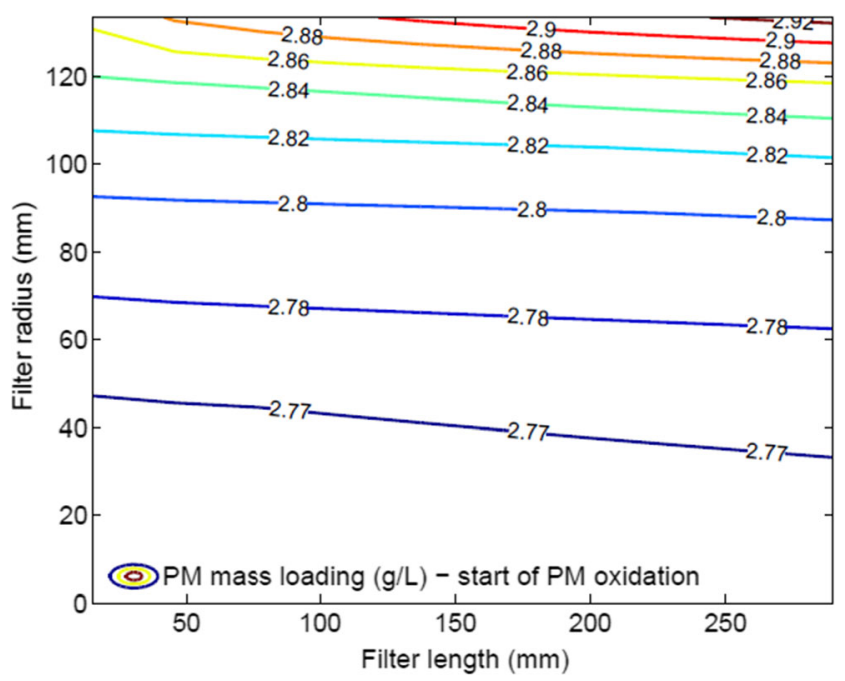

Fig. 30 Simulated PM mass loading distribution along axial and radial directions at $5.38 \mathrm{~h}$ (start of active regeneration) for the AR-B10-1 experiment

of PM oxidation (Fig. 31). The PM loading distribution is similar to the end of PM oxidation (minimum at the center of the filter and maximum at the outer radius of the filter) condition as shown in Fig. 31.

Figure 33 shows the axial and radial distribution of PM loading measured by Foley [16] for a similar active regeneration experiment $\left(526{ }^{\circ} \mathrm{C}\right.$ active regeneration temperature and $7.5 \% \mathrm{O}_{2}$ concentration at $\mathrm{CPF}$ inlet) with the post-active regeneration PM mass loading of $2.22 \mathrm{~g} / \mathrm{L}$ (PM loading before start of active regeneration was $3.06 \mathrm{~g} / \mathrm{L}$ ) using ULSD fuel.

Comparing Fig. 31 with Fig. 33, the MPF model and the experimental PM loading distribution shows the uniform loading of the filter substrate at the end of PM oxidation for the active regeneration experiment up to filter radiuses $66 \mathrm{~mm}$.

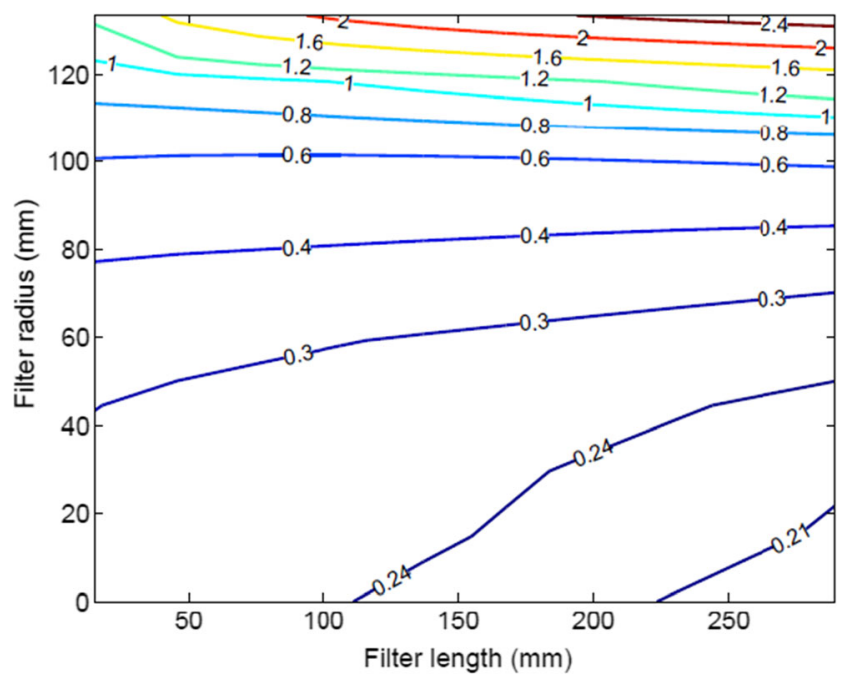

Fig. 31 Simulated PM mass loading distribution along axial and radial directions at $5.82 \mathrm{~h}$ (end of PM oxidation by active regeneration) for the AR-B10-1 experiment

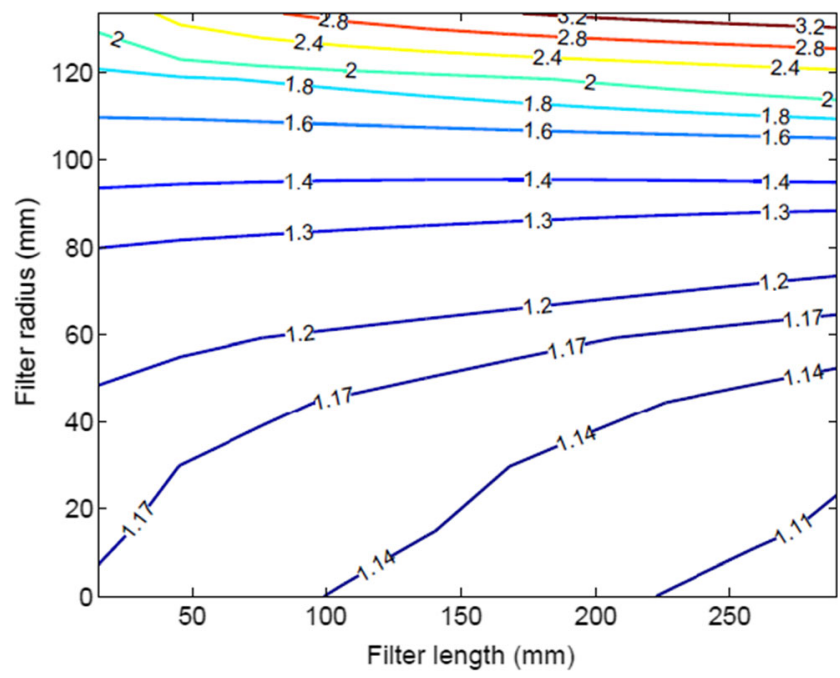

Fig. 32 Simulated PM mass loading distribution along axial and radial directions at $7.33 \mathrm{~h}$ (end of post-loading) for the AR-B10-1 experiment

The PM loading distribution in the simulation (Fig. 31) shows the small axial gradient between 0 and $66 \mathrm{~mm}$ filter radiuses ( 0.24 to $0.3 \mathrm{~g} / \mathrm{L})$. However, it is less than the $95 \%$ range given in Fig. $33(0.14 \mathrm{~g} / \mathrm{L}$ for filter radiuses up to $66 \mathrm{~mm})$. Hence, considering the small axial variation in the experiment and simulation data, the PM loading is uniform for simulation and experimental data up to filter radiuses $66 \mathrm{~mm}$. The experimental PM loading trend shows an increase in PM loading towards the end of the filter substrate $(5 \%$ higher than the average filter substrate loading). However, the MPF model shows a slight decrease in the PM loading trend till the middle section of the filter substrate $(R<80 \mathrm{~mm})$ and an increase in PM loading from the middle section to filter substrate outer radius sections $(R>80 \mathrm{~mm})$. The decrease in PM loading for filter radiuses less than $80 \mathrm{~mm}$ in the MPF model could be attributed to increased PM oxidation due to the higher temperature in the axial direction towards the middle to the end sections of the filter as shown in the temperature distribution plot (Fig. 26). The MPF model shows a consistent increase in PM loading towards the outer section of the filter substrate consistent with the reduction in the filter substrate temperature. The PM loading increase towards the outlet end of the filter could be explained by PM cake and ash transport mechanisms proposed by Sappok et al. [23] as explained in the passive oxidation results section. The experimental PM loading towards the outermost edge of the filter substrate shows a decrease in PM loading due to the lack of measurement capability of the terahertz wave scanner close to the wall surfaces.

Figure 34 shows the comparison of average (arithmetic), minimum, and maximum simulated PM mass loading distribution at the start $(5.38 \mathrm{~h})$ and end of the PM oxidation $(5.82 \mathrm{~h})$ for the AR-B10-1 experiment. The solid lines indicate the average PM mass loading for a given axial section (calculated by averaging the PM loading in all of the radial 
a) Radial Section 1- Diameter or 0-133 mm
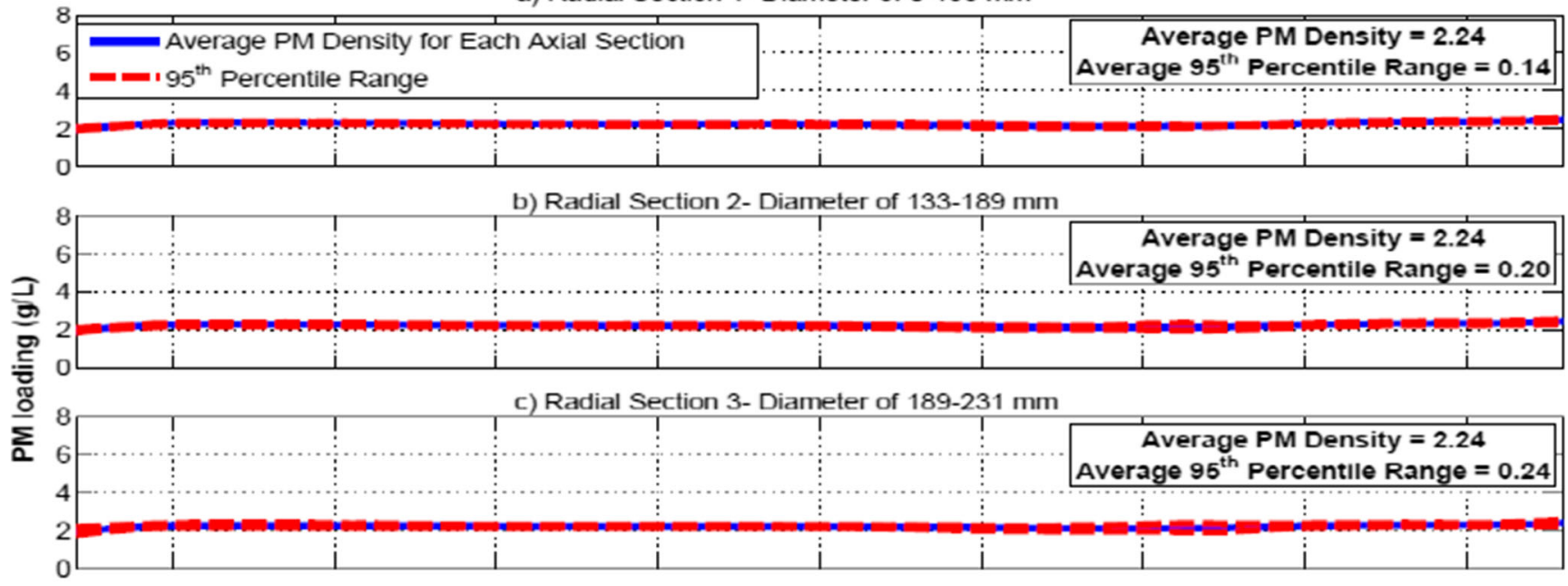

d) Radial Section 4- Diameter or $231-267 \mathrm{~mm}$

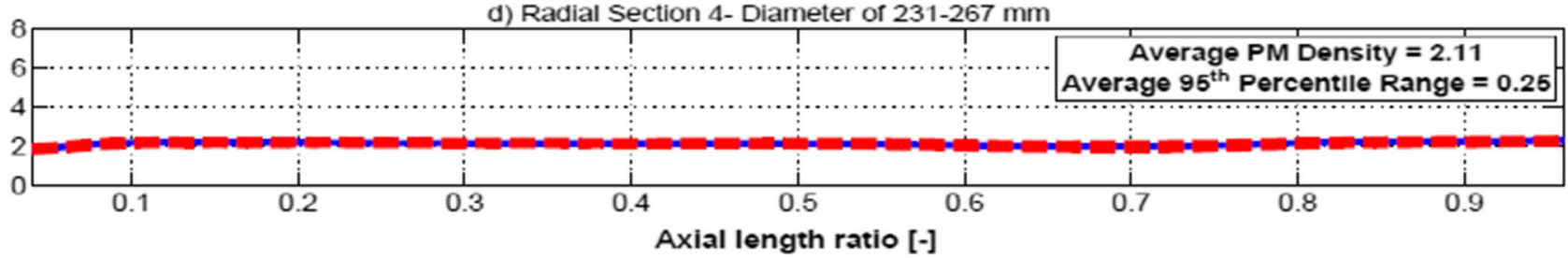

Fig. 33 Test 4 end of active regeneration $(A R)$ phase axial and radial PM distribution measured - adapted from reference [7] for 2007 ISL engine, axial length ratio of 1.0 corresponds to $305 \mathrm{~mm}$ filter length, axial uniformity index for plots $a-d$ are 0.97 , average radial uniformity index $=0.98$, and average angular uniformity index $=0.98$

lines. Hence, the $\mathrm{UI}_{\mathrm{PM}}$ is 0.98 , indicating more uniform PM loading within the filter. The simulated PM mass loading at the end of PM oxidation is shown by the subplot Fig. 34b. At the end of PM oxidation by active regeneration, the average PM loading is $0.60 \mathrm{~g} / \mathrm{L}$ and there is a slight increase $(0.51$ to $0.65 \mathrm{~g} / \mathrm{L}$ ) in average PM mass loading axially towards the end of the filter. The spread within each axial section is also increased (minimum loading $0.19 \mathrm{~g} / \mathrm{L}$ and maximum loading $2.4 \mathrm{~g} / \mathrm{L}$ ) as shown by the dotted lines. Hence, the $\mathrm{UI}_{\mathrm{PM}}$ at the end of PM oxidation is reduced to 0.00 indicating very non-uniform distribution within the filter.

Figure 35 shows the simulated average (arithmetic) PM mass loading distribution at the end of PM oxidation by active regeneration between the radial sections of the filter. From Fig. 35, the radial section 1 (diameter of 0 to $60 \mathrm{~mm}$ ) and radial section 2 (diameter of 60 to $148 \mathrm{~mm}$ ) shows a slight decrease (radial section 1: 0.28 to $0.21 \mathrm{~g} / \mathrm{L}$, radial section $2,0.39$ to $0.33 \mathrm{~g} / \mathrm{L}$ ) in PM loading towards end of the filter (axial ratio $=0.95)$. However, the radial section $3(148$ to $267 \mathrm{~mm}$, outer radiuses) shows an increase ( 0.92 to $1.56 \mathrm{~g} / \mathrm{L})$ in $\mathrm{PM}$ loading towards the end of the filter. Comparing filter loading at all three radial sections shows that most of the non-uniformity in PM loading distribution is from the radial section 3 because of the lower filter substrate temperature as shown by Fig. 26.

Figure 36 shows the simulated PM mass loading distribution at the end of post-loading for the AR-B10-1 experiment. From Fig. 36, the average PM mass loading increased from 


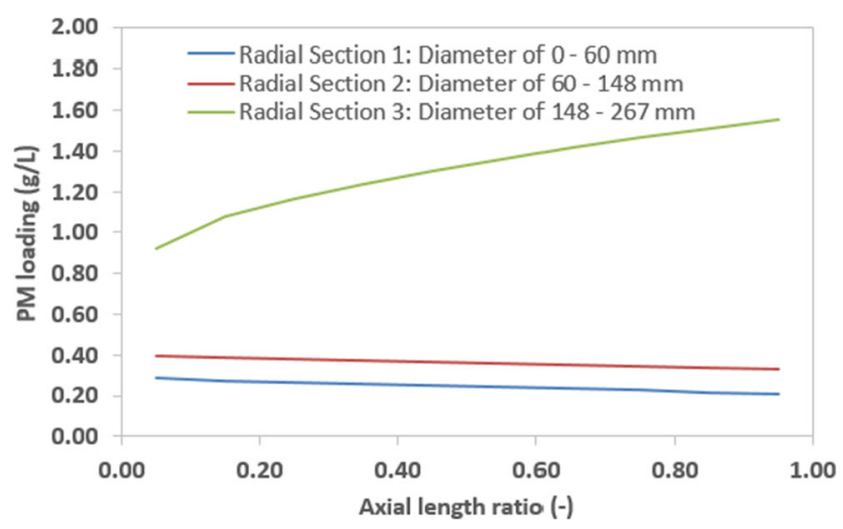

Fig. 35 Comparison of simulated average PM mass loading distribution at the end of PM oxidation $(5.82 \mathrm{~h}$ ) by active regeneration between radial sections for the AR-B10-1 experiment

$0.60 \mathrm{~g} / \mathrm{L}$ (at the start of post-loading) to $1.48 \mathrm{~g} / \mathrm{L}$ (at the end of post-loading) and the $\mathrm{UI}_{\mathrm{PM}}$ improved from 0.00 (at the start of post-loading in Fig. 34b) to 0.60. Comparing Figs. 34b and 36 , the range of PM loading distribution is similar (gap between the dashed lines - within $0.05 \mathrm{~g} / \mathrm{L}$ ); however, the increase in average PM loading resulted in improved $\mathrm{UI}_{\mathrm{PM}}$. Comparing Figs. 34 and 36, the PM loading is uniform at the beginning of the PM oxidation by active regeneration and becomes non-uniform at the end of PM oxidation and remains non-uniform until the end of post-loading. This implies that the PM oxidation by active regeneration causes the nonuniform PM loading distribution of the filter. This is mainly because of the variation in the overall PM reaction rates (as shown in Fig. 28) within the filter during active regeneration.

Figure 37 shows the PM cake layer thickness variation along the radial direction predicted by the MPF model for the AR-B10-1 experiment. From Fig. 37, PM cake layer thickness post-active regeneration varies significantly in the radial direction. At the end of post-loading, the PM cake layer thickness at the center of the filter was $12.3 \mu \mathrm{m}$ whereas the PM cake layer thickness was $22.3 \mu \mathrm{m}$ at the outer radius of the filter. This can be attributed to the lack of PM oxidation due to the lower filter substrate temperature as seen in the temperature distribution plot (Fig. 26).

Figures 38 and 39 show the PM cake layer thickness variation along the axial direction for the center zone and outermost zone of the filter substrate predicted by the MPF model for the AR-B10-1 experiment. From Figs. 38 and 39, PM cake layer thickness is uniform axially during the loading phase of the experiment (from 0 to $4.98 \mathrm{~h}$ ) whereas during active regeneration (approximately $5 \mathrm{~min}$ after changing to AR engine conditions) and post-loading (from 5.82 to $7.33 \mathrm{~h}$ ) the PM cake layer thickness varies non-uniformly in Figs. 38 and 39. The cake layer thickness at the end of post-loading $(7.33 \mathrm{~h})$ is minimum at the inlet of the filter substrate $(\mathrm{x} / \mathrm{L}=0$, cake layer thickness $=$ $22.1 \mu \mathrm{m})$ and maximum at the outlet of the filter substrate $(\mathrm{x} / \mathrm{L}=1.0$, cake layer thickness $=36.9 \mu \mathrm{m})$.

\subsection{Summary of PO and AR Model Results}

Table 5 shows the summary of MPF model results for PO-B1015 and AR-B10-1 experiments. From Table 5, active regeneration experiment (AR-B10-1) shows higher radial temperature drop $\left(\cong 40{ }^{\circ} \mathrm{C}\right.$ at $\left.\mathrm{x} / \mathrm{L}=0.5\right)$ after $15 \mathrm{~min}$ into the $\mathrm{PM}$ oxidation phase compared to the passive oxidation experiment (PO-B1015). The temperature uniformity index of the passive oxidation and active regeneration experiment is similar $\left(\mathrm{UI}_{\mathrm{T}}=0.96\right.$ to
Fig. 36 Comparison of average (solid lines), minimum, and maximum (dashed lines) simulated PM mass loading distribution at the end of postloading $(7.33 \mathrm{~h})$ for the AR-B101 experiment

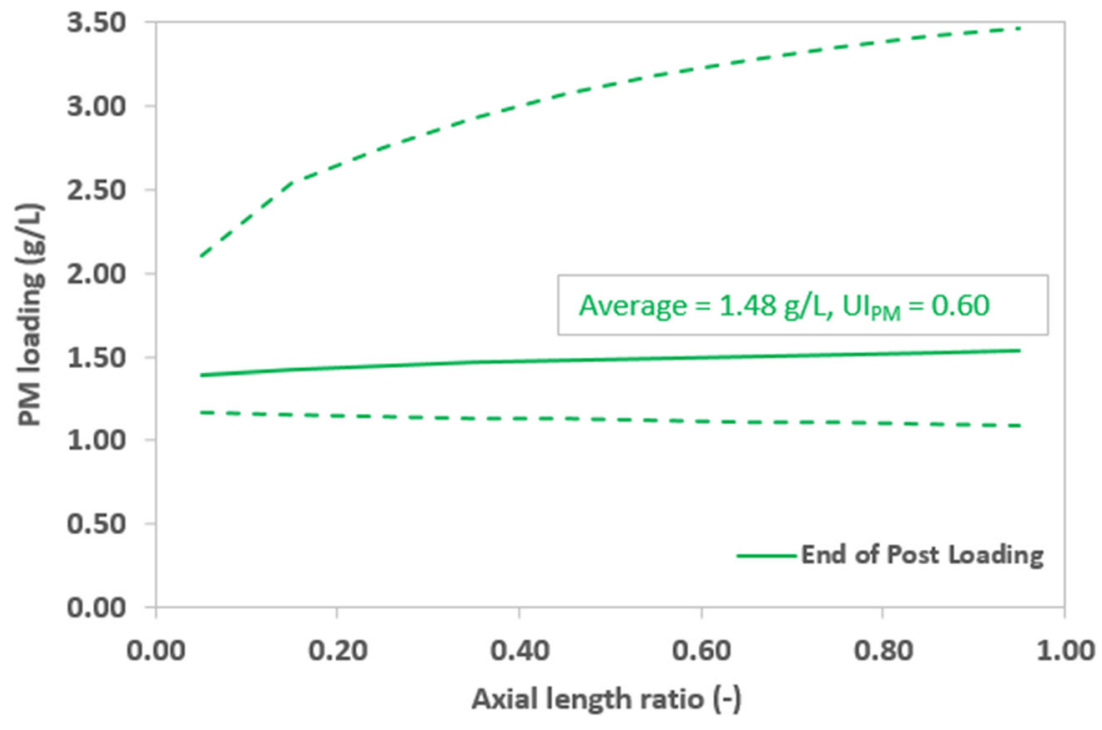

Dashed lines: Minimum and maximum PM loading simulated by the MPF model at the end of post loading 


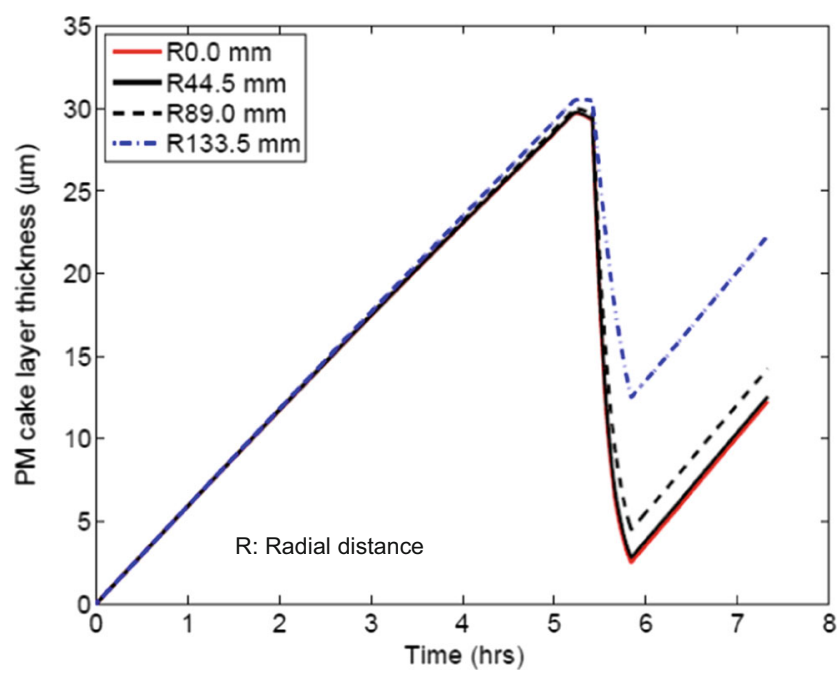

Fig. 37 Simulated PM cake layer thickness variation along radial direction at the filter substrate inlet (15.2 $\mathrm{mm}$ from inlet axial direction) for the AR-10-1 experiment

0.97-after 15 min into the PM oxidation phase). However, the overall reaction rate uniformity index of the active regeneration experiment $\left(\mathrm{UI}_{\mathrm{RR}}\right.$ for passive oxidation is 0.73 to 0.80 versus 0.63 to 0.61 in the case of active regeneration) is lower than the passive oxidation experiment. This is mainly due to the exponential relationship of the temperature (and its variation) with the Arrhenius reaction rate of the PM oxidation.

Comparing the simulated PM density loading distribution between the passive oxidation and active regeneration experiments, passive oxidation shows less variation in PM loading distribution $(0.9$ to $1.9 \mathrm{~g} / \mathrm{L})$ compared to the active regeneration $(0.2$ to $2.6 \mathrm{~g} / \mathrm{L})$ experiment throughout the entire filter. However, the active regeneration test conditions reach the lowest PM density loading $(0.2 \mathrm{~g} / \mathrm{L})$ and PM cake layer thickness $(12.3 \mu \mathrm{m})$ at the center zones of the filter, due to the high

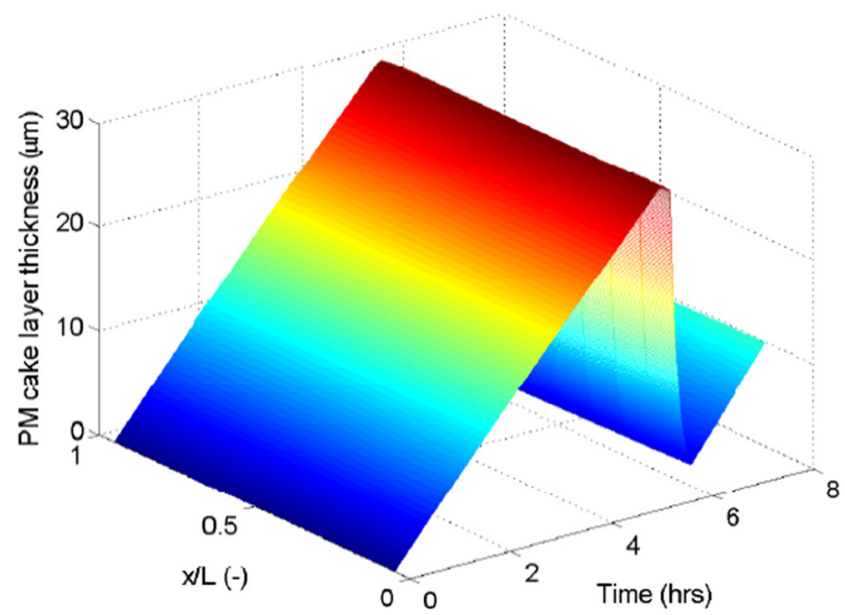

Fig. 38 Simulated PM cake layer thickness distribution along axial and radial directions at the center of the filter $(R=0 \mathrm{~mm})$ for the entire test duration for the AR-B10-1 experiment

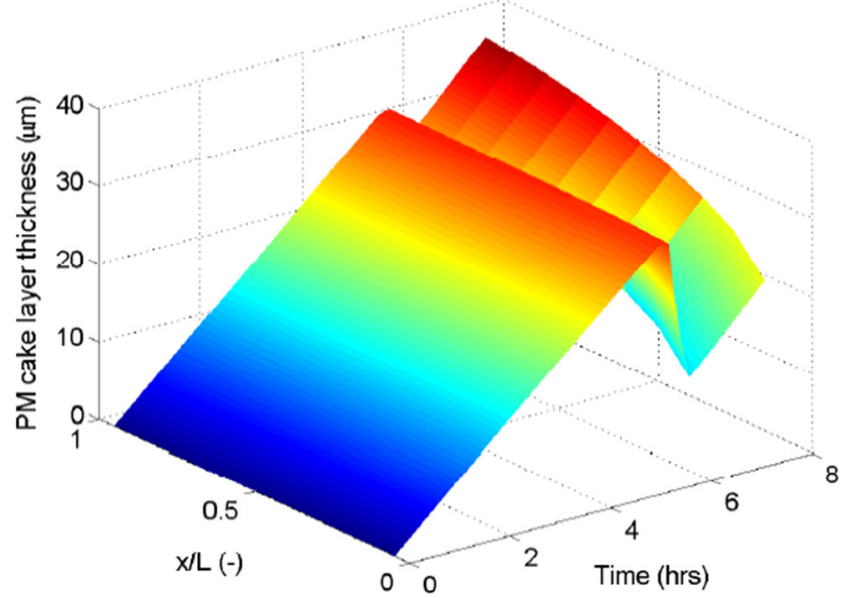

Fig. 39 Simulated PM cake layer thickness distribution along axial and radial directions at the outermost zone of the filter $(R=133.5 \mathrm{~mm})$ for the entire test duration for the AR-B10-1 experiment

temperature PM oxidation for active regeneration that oxidizes the PM at a higher rate compared to the passive oxidation experiment test conditions.

Comparing the PM loading distribution (uniformity index) between passive oxidation and active regeneration experiments, the PM loading is uniform at the start of PM oxidation $\left(\mathrm{UI}_{\mathrm{PM}}=\right.$ 0.98 to 0.99 ) for passive and active regeneration experiments. However, at the end of PM oxidation, the $\mathrm{UI}_{\mathrm{PM}}$ reduces to 0.78 for the passive oxidation experiment and reduces to 0.00 for the active regeneration experiment. This implies that the PM oxidation by active regeneration shows more non-uniform PM distribution compared to passive oxidation experiment. The post-loading of the filter increases the PM uniformity index (UI $_{\mathrm{PM}}$ increases from 0.78 to 0.87 for passive oxidation and 0.00 to 0.60 for active regeneration) because of the increased average loading in the filter (passive oxidation $1.09 \mathrm{~g} / \mathrm{L}$ to $1.96 \mathrm{~g} / \mathrm{L}$, active regeneration $0.60 \mathrm{~g} / \mathrm{L}$ to $1.48 \mathrm{~g} / \mathrm{L}$ ) compared to end of PM oxidation test conditions.

Overall, the comparison of the experimental results to the MPF model confirms this model can predict temperature and filter loading distribution within reasonable agreement with the experimental measurements.

\subsection{Analysis of PM Mass Oxidized}

Figure 40 shows the fraction of $\mathrm{PM}$ mass oxidized by $\mathrm{NO}_{2}$ assisted and thermal $\left(\mathrm{O}_{2}\right)$ assisted $\mathrm{PM}$ oxidation reactions. The sum of these fractions will be equal to 1 . Table 10 in Appendix 2 shows the fractional PM mass oxidized during passive oxidation and active regeneration phases for all 18 experiments simulated by the MPF model presented in this study. Curve fit results from the Michigan Technological University (MTU) 1-D model [13] are also included to compare with 
Table 5 Summary of MPF model results for PO-B10-16 and AR-B10-1 experiment simulation results from the MPF model. There is a good agreement between simulated fractions from both models. For the temperatures below $400{ }^{\circ} \mathrm{C}$, PM oxidation is dominated by the $\mathrm{NO}_{2}$ assisted PM oxidation mechanism ( $>90 \%$ of PM oxidized). However, for temperatures over $500{ }^{\circ} \mathrm{C}$, the PM oxidation is dominated by the thermal $\left(\mathrm{O}_{2}\right)$ assisted PM oxidation mechanism $(>70 \%$ of PM oxidized).

\subsection{Thermal PM Oxidation by Fuel Type}

Figure 41 shows the fraction of thermal $\left(\mathrm{O}_{2}\right)$ PM oxidation for ULSD, B10, and B20 fuels. From Fig. 41, the B20 fuel shows increased PM oxidation rate compared to B10 and ULSD fuels. While comparing the temperature required for $50 \%$ of thermal PM oxidation between the fuels, the $\mathrm{B} 20$ fuel requires about $10{ }^{\circ} \mathrm{C}$ lower temperature than that of the B10 fuel and requires about $57^{\circ} \mathrm{C}$ lower temperature than that of the ULSD fuel. This is mainly due to the increased reaction rate for B20 and B10 fuels compared to ULSD fuels as shown in Fig. 10. The increased PM oxidation rate from the above analysis is in agreement with the earlier research work on the blended B20 biodiesel. Boehman et al. [24] showed that the blended biodiesel alters the composition and nanostructure of the PM and increased the burn rates of the PM stored in the CPF. Vertin et al. [25] also showed an increased regeneration efficiency with B20 biodiesel compared to ULSD fuels.

\subsection{Regeneration Time Based on Fuel Type}

The PM regeneration time during the experimental conditions varies based on inlet concentrations $\left(\mathrm{O}_{2}\right.$ and $\left.\mathrm{NO}_{2}\right)$, filter 


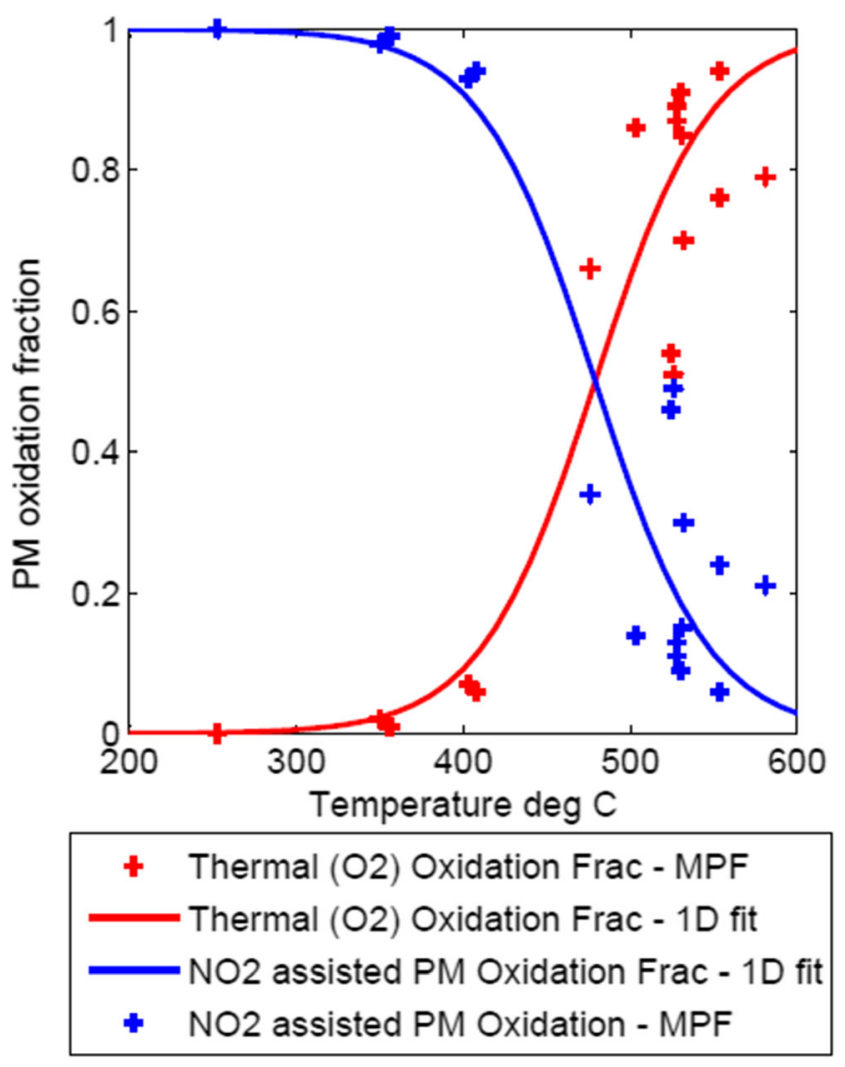

Fig. 40 Fraction of total $\mathrm{PM}$ mass oxidized by thermal and $\mathrm{NO}_{2}$-assisted $\mathrm{PM}$ oxidation reactions plotted against average $\mathrm{CPF}$ temperature during passive and active regeneration stages of all eighteen experiments in this study. The curve fits are taken from reference [13] for the 1-D model

temperature, PM inlet rate, etc. Hence, in order to study the effect of fuel type on regeneration time, a separate Matlab script was written to simulate the PM oxidation in the loaded filter with the initial loading of $43.2 \mathrm{~g}$ at $554{ }^{\circ} \mathrm{C}$ (similar to AR-ULSD-1 test conditions). The Matlab script executes PM oxidation by solving Eqs. 2 to 4 recursively for $15 \mathrm{~min}$, and the resultant PM mass

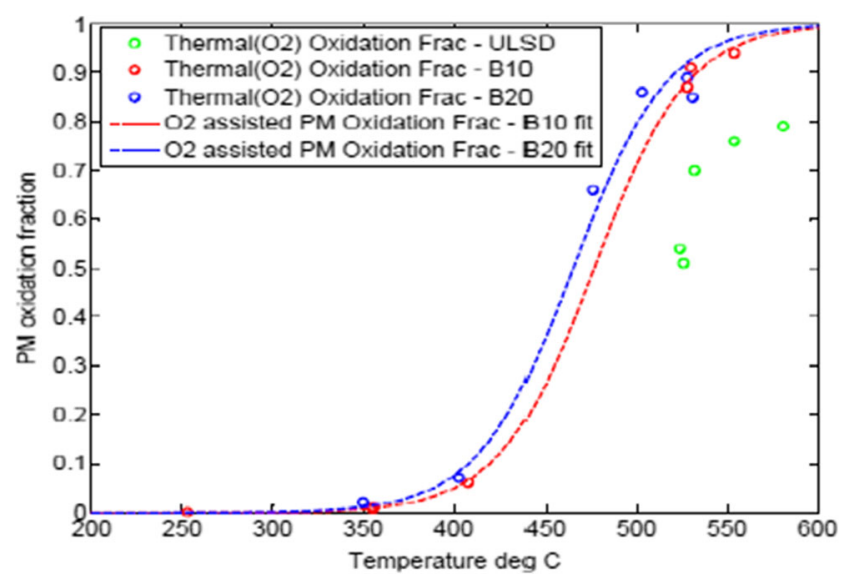

Fig. 41 Fraction of total PM mass oxidized by thermal PM oxidation reactions plotted against average CPF temperature for ULSD, B10, and B20 fuel retained is plotted in Fig. 42 in terms of regeneration time versus PM mass retained fraction (PM mass retained / initial PM mass). The purpose of this study is to quantify the regeneration time differences between the fuels caused by the differences in PM kinetics (activation energy and pre-exponential factors). Figure 42 shows the PM-retained fraction in the filter as a function of regeneration time from the initial loading. From Fig. 42, comparing the PM mass retained at the end of 8 min into the PM oxidation, $59 \%$ of initial mass was retained while using ULSD fuel, $33 \%$ of initial mass was retained with B10 fuel, and $18 \%$ of initial mass was retained with B20 fuel. From this analysis, the B20 and B10 fuels show higher PM oxidation rates and require shorter regeneration time compared to ULSD fuel. Comparing regeneration time between fuels, for oxidation of $50 \%$ of initial PM mass used in this study, the B10 fuel was 5.32 min (51\%) faster than the ULSD fuel and B20 was 7.07 min (68 \%) faster than the ULSD fuel.

\section{Summary and Conclusions}

A MPF model developed in reference [1] was further extended to include UI analysis for temperature and filter PM loading distribution analysis within the filter. The MPF model was also applied and compared with extensive engine experimental data for wide operating conditions covering 6 passive oxidation and 12 active regeneration cases. In addition, the PM distribution trends from the MPF model were compared with experimental data from the terahertz wave scanner. The MPF model showed maximum absolute PM loading error of $3.8 \mathrm{~g}$ and RMS error of $2.1 \mathrm{~g}$ for all 18 experimental runs. From the experimental data presented in this paper for PO-B10-15 and AR-B10-1 experiments, the maximum RMS temperature error was within $10^{\circ} \mathrm{C}$.

A discretization study was conducted to determine the effect of the number of axial/radial zones on model run time and accuracy related to simulating temperature and PM loading distribution. The study showed that the MPF model with $10 \times 10$ zones has the optimum size with a good compromise between model run time and accuracy.

The specific findings from this work include

1. The $10 \times 10$ zone MPF model showed computation time of 12.2 times faster than real time. Using optimized C language codes for the ECU, the MPF model should be able to run in real time with the ECU for temperature and PM loading distribution estimation and control.

2. Temperatures within the filter substrate varies radially and axially. The radial temperature variation is significant and it is up to $\cong 32{ }^{\circ} \mathrm{C}$ during $\mathrm{PM}$ oxidation by passive oxidation and $\cong 40{ }^{\circ} \mathrm{C}$ during active regeneration. The axial temperature variation is small and it is $\cong 12{ }^{\circ} \mathrm{C}$ for active regeneration experiment and nearly not noticeable 
Fig. 42 Simulated PM mass retained for ULSD, B10, and B20 fuels for initial PM mass of $43.2 \mathrm{~g}$ and active regeneration at $554{ }^{\circ} \mathrm{C}$

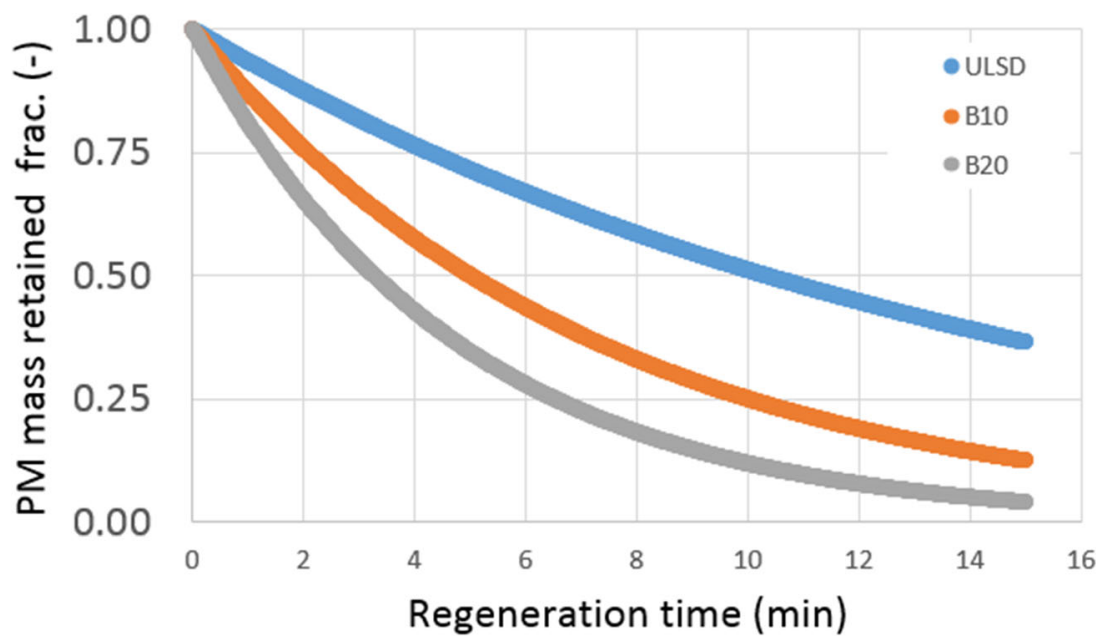

$\left(\cong 2{ }^{\circ} \mathrm{C}\right.$ ) for the passive oxidation experiment. The $\mathrm{UI}_{\mathrm{T}}$ during PM oxidation for passive oxidation is almost similar to that of active regeneration $\left(\mathrm{UI}_{\mathrm{T}}=0.96\right.$ to 0.97$)$.

3. For a similar $\mathrm{UI}_{\mathrm{T}}$ (i.e., 0.96 to 0.97 ) during $\mathrm{PM}$ oxidation (passive oxidation and active regeneration), the $\mathrm{UI}_{\mathrm{RR}}$ is 0.73 to 0.80 during passive oxidation and 0.63 to 0.61 during active regeneration test conditions. The average overall reaction rate for active regeneration is 7.5 to 8.5 times higher than the passive oxidation reaction rate causing more non-uniform PM distribution for active regeneration conditions of the filter.

4. The simulated PM loading is uniform (within $+/-0.1 \mathrm{~g} /$ L) up to the filter radius of $80 \mathrm{~mm}(\mathrm{CPF}$ diameter ratio= 0.52 ) at the end of PM oxidation (passive oxidation and active regeneration) and increases to a maximum value (1.9 $\mathrm{g} / \mathrm{L}$ for passive oxidation and $2.6 \mathrm{~g} / \mathrm{L}$ for active regeneration) at the outer radius of the filter substrate.

5. The radial PM non-uniformity is strongly affected by the radial temperature distribution. This is mainly because of the radial heat losses from the exhaust system and the CPF. Though the double wall thermal insulation is applied on the CPF, the radial temperature distribution initiates much before the inlet of the CPF and affects temperature and PM loading distribution in the entire CPF.

6. The active regeneration of the filter leads to non-uniform loading (minimum PM density loading of $0.2 \mathrm{~g} / \mathrm{L}$ and maximum PM density loading of $2.6 \mathrm{~g} / \mathrm{L}$ at the end of active regeneration) of the filter compared to the passive oxidation test conditions (minimum PM density loading of $0.9 \mathrm{~g} / \mathrm{L}$ and maximum PM density loading of $1.9 \mathrm{~g} / \mathrm{L}$ at the end of passive oxidation).

7. The PM loading is uniform at the start of PM oxidation $\left(\mathrm{UI}_{\mathrm{PM}}=0.98\right.$ to 0.99$)$ and becomes non-uniform at the end of PM oxidation by passive oxidation and active regeneration $\left(\mathrm{UI}_{\mathrm{PM}}\right.$ at the end of $\mathrm{PM}$ oxidation by passive oxidation is 0.78 and by active regeneration is 0.00 ). The non-uniform PM loading distribution continued until the end of the post-loading $\left(\mathrm{UI}_{\mathrm{PM}}\right.$ at the end of post-loading was 0.87 and 0.60 for passive oxidation and active regeneration experiments respectively).

8. The $\mathrm{NO}_{2}$ assisted and thermal $\left(\mathrm{O}_{2}\right) \mathrm{PM}$ oxidation mechanisms aid in oxidizing the PM mass retained within the filter over a wide temperature range $\left(200\right.$ to $\left.600^{\circ} \mathrm{C}\right)$. For temperatures below $400{ }^{\circ} \mathrm{C}$, thermal $\left(\mathrm{O}_{2}\right) \mathrm{PM}$ oxidation is less than $10 \%$ and most of the PM $(>90 \%)$ is oxidized by the $\mathrm{NO}_{2}$ assisted PM oxidation mechanism and for temperatures over $500{ }^{\circ} \mathrm{C}, \mathrm{PM}$ oxidation by $\mathrm{NO}_{2}$ assisted mechanism is below $30 \%$ and the thermal $\left(\mathrm{O}_{2}\right)$ assisted mechanism oxidizes over $70 \%$ of PM mass retained.

9. The B20 fuel showed increased reaction rate compared to B10 and ULSD fuels during thermal PM oxidation. The activation energy $\left(E_{\mathrm{O}_{2}}\right)$ of B20 fuel is $1.9 \%$ lower than the B10 fuel and $5.8 \%$ lower than the ULSD fuel. The increased reaction rate of B20 fuel lowers $50 \%$ thermal $\mathrm{PM}$ oxidation fraction temperature by $\cong 10{ }^{\circ} \mathrm{C}$ compared to $\mathrm{B} 10$ fuel and $\cong 57^{\circ} \mathrm{C}$ compared to ULSD fuel.

10. The increased reaction rate of $\mathrm{B} 20$ fuel reduces the time required for active regeneration of the $\mathrm{CPF}$ under the same PM initial load and temperature compared to B10 and ULSD fuels. Comparing regeneration time between fuels, for oxidation of $50 \%$ of initial PM mass used in this study, the B10 fuel was $5.32 \mathrm{~min}(51 \%)$ faster than the ULSD fuel and B20 was 7.07 min (68\%) faster than the ULSD fuel.

\section{Nomenclature}

$A_{\mathrm{O}_{2}} \quad$ Pre-exponential for thermal $\left(\mathrm{O}_{2}\right)$ PM oxidation $\left[\mathrm{m} \mathrm{K}^{-1} \mathrm{~s}^{-1}\right]$

$A_{\mathrm{NO}_{2}} \quad$ Pre-exponential for $\mathrm{NO}_{2}$ assisted PM oxidation $\left[\mathrm{m} \mathrm{K}^{-1} \mathrm{~s}^{-1}\right.$ ]

$c_{f} \quad$ Specific heat of filter material $\left[\mathrm{J} \mathrm{kg}^{-1} \mathrm{~K}^{-1}\right]$ 


\begin{tabular}{|c|c|c|c|}
\hline $\mathrm{C}_{\mathrm{NO}_{2}}$ & $\mathrm{CPF}$ inlet $\mathrm{NO}_{2}$ concentration $\left[\mathrm{mg} \mathrm{m}^{-3}\right]$ & $V_{f}$ & Volume of filter in each zone $\left[\mathrm{m}^{3}\right]$ \\
\hline$C_{\mathrm{O}_{2}}$ & $\mathrm{CPF}$ inlet $\mathrm{O}_{2}$ concentration $\left[\mathrm{mg} \mathrm{m}^{-3}\right]$ & $V_{s}$ & PM cake volume in each zone $\left[\mathrm{m}^{3}\right]$ \\
\hline$C_{P M}$ & $\mathrm{CPF}$ inlet $\mathrm{PM}$ concentration $\left[\mathrm{mg} \mathrm{m}^{-3}\right]$ & $W$ & exhaust gas molecular weight $\left[\mathrm{kg} \mathrm{kmol}^{-1}\right]$ \\
\hline$C_{s}$ & Specific heat of PM cake $\left[\mathrm{J} \mathrm{kg}^{-1} \mathrm{~K}^{-1}\right]$ & $W_{C}$ & Molecular weight of carbon $\left[\mathrm{kg} \mathrm{kmol}^{-1}\right]$ \\
\hline$E_{\mathrm{NO}_{2}}$ & Activation energy for $\mathrm{NO}_{2}$ assisted $\mathrm{PM}$ oxidation & $W_{\mathrm{O}_{2}}$ & Molecular weight of oxygen $\left[\mathrm{kg} \mathrm{kmol}^{-1}\right]$ \\
\hline$E_{O_{2}}$ & $\begin{array}{l}{\left[\mathrm{J} \mathrm{gmol}^{-1}\right]} \\
\text { Activation energy for thermal }\left(\mathrm{O}_{2}\right) \mathrm{PM} \text { oxidation }\end{array}$ & $W_{\mathrm{NO}_{2}}$ & $\begin{array}{l}\text { Molecular weight of nitrogen dioxide }[\mathrm{kg} \\
\left.\mathrm{kmol}^{-1}\right]\end{array}$ \\
\hline & {$\left[\mathrm{J} \mathrm{gmol}^{-1}\right]$} & Y & Mass fractions $[-]$ \\
\hline$k_{\mathrm{NO}_{2}}$ & Rate constant for $\mathrm{NO}_{2}$ assisted PM oxidation & $Y_{i, j_{N O_{2}}}$ & Mass fraction of inlet $\mathrm{NO}_{2}$ at each zone [-] \\
\hline$k_{O_{2}}$ & $\begin{array}{l}\text { Rate constant for } O_{2} \text { assisted PM oxidation } \\
{\left[\mathrm{m} \mathrm{s}^{-1}\right]}\end{array}$ & & \\
\hline$\dot{m}$ & Instantaneous exhaust mass flow rate $\left[\mathrm{kg} \mathrm{s}^{-1}\right]$ & \multirow{2}{*}{\multicolumn{2}{|c|}{ Greek variables }} \\
\hline$\dot{m}_{i, j}$ & Mass flow rate at each zone $\left[\mathrm{kg} \mathrm{s}^{-1}\right]$ & & \\
\hline$\dot{m} s_{i, j}$ & Mass of PM in each zone $[\mathrm{kg}]$ & $a_{O_{2}}$ & $\mathrm{O}_{2}$ oxidation partial factor $[-]$ \\
\hline$\dot{m}_{\text {total }}$ & Total mass flow rate into CPF $\left[\mathrm{kg} \mathrm{s}^{-1}\right]$ & $a_{N_{2}}$ & $\mathrm{NO}_{2}$ oxidation partial factor $[-]$ \\
\hline$P_{\text {in }}$ & $\mathrm{CPF}$ inlet gas pressure $[\mathrm{kPa}]$ & $\rho$ & Exhaust gas density $\left[\mathrm{kg} \mathrm{m}^{-3}\right]$ \\
\hline$Q_{\text {cond,axial }}$ & Axial conduction $[\mathrm{W}]$ & $\rho_{f}$ & Filter density $\left[\mathrm{kg} \mathrm{m}^{-3}\right]$ \\
\hline$Q_{\text {cond,radial }}$ & Radial conduction $[\mathrm{W}]$ & $\rho_{S}$ & PM cake density $\left[\mathrm{kg} \mathrm{m}^{3}{ }^{3}\right]$ \\
\hline$Q_{\text {conv }}$ & $\begin{array}{l}\text { Convection between channels gases and filter } \\
\text { wall [W] }\end{array}$ & $\sigma_{P M}$ & $\begin{array}{l}\text { Standard deviation of the PM mass loading over } \\
\text { the entire filter [-] }\end{array}$ \\
\hline$\dot{Q}_{\mathrm{rad}}$ & Radiation between channel surfaces [W] & $\sigma_{R R}$ & Standard deviation of the overall reaction rate \\
\hline$\dot{Q}_{\text {reac }}$ & PM cake exothermic reactions $[\mathrm{W}]$ & & over the entire filter $[-]$ \\
\hline$R R_{\mathrm{ov}}$ & Overall reaction rate $\left[\mathrm{s}^{-1}\right]$ & $\sigma_{T}$ & Standard deviation of the filter substrate \\
\hline$R_{u}$ & Universal gas constant $\left[\mathrm{J} \mathrm{gmol}^{-1} \mathrm{~K}^{-1}\right]$ & & temperature over the entire filter $[-]$ \\
\hline$S_{p}$ & Specific surface area of PM $\left(5.5 \times 10^{7}\right)\left[\mathrm{m}^{-1}\right]$ & $\mu_{P M}$ & Average PM mass loading over the entire filter \\
\hline$T_{f}$ & Temperature of combined filter and PM cake $[\mathrm{K}]$ & & {$[-]$} \\
\hline$T_{\text {in }}$ & CPF inlet temperature $[\mathrm{K}]$ & $\mu_{R R}$ & Average overall reaction rate over the entire filter \\
\hline ts & PM cake thickness $[\mathrm{m}]$ & & {$[-]$} \\
\hline$\overline{t s}$ & $\begin{array}{l}\text { Average PM cake thickness across entire CPF } \\
{[\mathrm{m}]}\end{array}$ & $\mu_{T}$ & $\begin{array}{l}\text { Average filter substrate temperature over the } \\
\text { entire filter }[-]\end{array}$ \\
\hline
\end{tabular}

\section{Subscripts and Superscripts \\ i Radial Direction, $j$ Axial Direction}

Acknowledgments The authors would like to thank Kenneth Shiel and James Pidgeon, of Michigan Technological University for recording the temperature distribution data presented in this work and Dr. Kiran Premchand for assistance in 1-D model simulation data presented in this work. 


\section{Appendices}

\section{Appendix 1: Experimental Data}

Table 6 Passive oxidation experiments used for the calibration of the multi-zone model [2, 13]

\begin{tabular}{|c|c|c|c|c|c|c|}
\hline \multirow[t]{2}{*}{ No } & \multirow[t]{2}{*}{ Test ID } & \multicolumn{5}{|c|}{ Passive oxidation } \\
\hline & & Temp ${ }^{\circ} \mathrm{C}$ & Duration (min) & CPF Inlet NO2/NOx (ppm/ppm) & CPF inlet $\mathrm{O} 2(\% \mathrm{Vol})$. & PM mass retained end of post-loading $(\mathrm{g})$ \\
\hline 1 & PO-B10-14 & 253 & 101 & $112 / 257$ & 12.6 & 50.8 \\
\hline 2 & PO-B10-15 & 355 & 81 & $101 / 194$ & 8.9 & 36.9 \\
\hline 3 & PO-B10-16 & 408 & 43 & $61 / 209$ & 7.1 & 35.1 \\
\hline 4 & PO-B10-17 & 356 & 80 & $90 / 178$ & 8.7 & 39.4 \\
\hline 5 & PO-B20-12 & 350 & 81 & $109 / 206$ & 9.4 & 37.1 \\
\hline 6 & PO-B20-13 & 403 & 42 & $64 / 204$ & 7.3 & 36.1 \\
\hline
\end{tabular}

Test ID nomenclature-PO-B10-14 means Passive Oxidation Experiment with B10 fuel type and experiment run 14

Table 7 Active regeneration experiments used for the calibration of the multi-zone model [3, 13]

\begin{tabular}{|c|c|c|c|c|c|c|}
\hline \multirow[t]{2}{*}{ No test ID } & \multirow[t]{2}{*}{ Temp } & \multicolumn{5}{|c|}{ Active regeneration } \\
\hline & & Temp ${ }^{\circ} \mathrm{C}$ & $\begin{array}{l}\text { Duration } \\
\text { (min) }\end{array}$ & $\begin{array}{l}\text { CPF inlet NO2/NOx } \\
(\mathrm{ppm} / \mathrm{ppm})\end{array}$ & $\begin{array}{l}\text { CPF inlet } \\
\text { O2 (\% Vol.) }\end{array}$ & $\begin{array}{l}\text { PM mass retained } \\
\text { end of post-loading }(g)\end{array}$ \\
\hline 1 & AR-ULSD-1 & 554 & 15 & $4 / 106$ & 7.2 & 38.4 \\
\hline 2 & AR-ULSD-2 & 581 & 6 & $7 / 141$ & 6.9 & 27.7 \\
\hline 3 & AR-ULSD-4 & 526 & 21 & $8 / 122$ & 7.6 & 35.9 \\
\hline 4 & AR-ULSD-5 & 524 & 22 & $6 / 131$ & 7.7 & 37.1 \\
\hline 5 & AR-ULSD-6 & 532 & 21 & $4 / 130$ & 7.7 & 35.8 \\
\hline 6 & AR-B10-1 & 530 & 26 & $4 / 119$ & 7.8 & 27.9 \\
\hline 7 & AR-B10-2 & 528 & 19 & $7 / 110$ & 7.8 & 27.4 \\
\hline 8 & AR-B10-4 & 554 & 15 & $3 / 124$ & 7.5 & 29.1 \\
\hline 9 & AR-B20-1 & 476 & 35 & $10 / 152$ & 8.8 & 33.0 \\
\hline 10 & AR-B20-2 & 503 & 39 & $4 / 138$ & 8 & 23.0 \\
\hline 11 & AR-B20-5 & 528 & 19 & $7 / 140$ & 8.2 & 18.4 \\
\hline 12 & AR-B20-6 & 531 & 16 & $10 / 124$ & 8.2 & 23.1 \\
\hline
\end{tabular}

Test ID nomenclature-AR-ULSD-1 means Active Regeneration Experiment with ULSD fuel type and experiment run 1 
Table 8 Thermocouple specifications $[4,5]$

\begin{tabular}{llllll}
\hline Location & Type & $\begin{array}{l}\text { Diameter } \\
(\mathrm{mm})\end{array}$ & $\begin{array}{l}\text { Length(s) } \\
(\mathrm{mm})\end{array}$ & Watlow P/N & Body material \\
\hline DOC & $\mathrm{K}$ & 0.508 & $304.8,431.8$ & AX1078701, PT-227664-001 & Inconel \\
CPF & $\mathrm{K}$ & 0.813 & $304.8,431.8$ & AX1078801, special order & Inconel \\
Engine exhaust & $\mathrm{K}$ & 3.175 & 152.5 & ACGF00Q060U40000 & Inconel \\
\hline
\end{tabular}

\section{Appendix 2-MPF Model Validation Results}

Table 9 Comparison of experimental and model PM mass retained using calibration parameters from reference [1]

\begin{tabular}{|c|c|c|c|c|c|c|c|c|c|c|c|c|c|}
\hline \multirow[t]{3}{*}{$\mathrm{No}$} & \multirow[t]{3}{*}{ Expt. name } & \multicolumn{12}{|c|}{ PM retained $[\mathrm{g}]$} \\
\hline & & \multicolumn{3}{|c|}{ Stage-1 } & \multicolumn{3}{|c|}{ Stage-2 } & \multicolumn{3}{|c|}{ Stage-3 } & \multicolumn{3}{|c|}{ Stage-4 } \\
\hline & & Expt. & Model & Diff. & Expt. & Model & Diff. & Expt. & Model & Diff. & Expt. & Model & Diff. \\
\hline 1 & PO-B10-14 & 4.3 & 4.4 & 0.1 & 36.4 & 37.7 & 1.3 & 42.8 & 43.8 & 1.0 & 50.8 & 52.4 & 1.6 \\
\hline 2 & PO-B10-15 & 4.6 & 4.7 & 0.1 & 35.9 & 36.9 & 1.0 & 27.0 & 24.7 & 2.3 & 36.9 & 34.6 & -2.3 \\
\hline 3 & PO-B10-16 & 4.3 & 4.3 & 0.0 & 36.5 & 37.8 & 1.3 & 26.0 & 26.6 & 0.6 & 35.1 & 35.9 & 0.8 \\
\hline 4 & PO-B10-17 & 4.6 & 4.7 & 0.1 & 37.0 & 38.8 & 1.8 & 29.8 & 26.9 & 2.9 & 39.4 & 35.6 & -3.8 \\
\hline 5 & PO-B20-12 & 3.6 & 3.8 & 0.2 & 39.1 & 41.5 & 2.4 & 28.9 & 27.1 & -1.8 & 37.1 & 34.7 & -2.4 \\
\hline 6 & PO-B20-13 & 4.0 & 4.2 & 0.2 & 38.5 & 40.8 & 2.3 & 27.2 & 24.8 & 2.4 & 36.1 & 33.4 & -2.7 \\
\hline 7 & AR-ULSD-1 & 6.0 & 6.9 & 0.9 & 44.3 & 43.3 & -1.0 & 25.2 & 27.2 & 2.0 & 38.4 & 39.9 & 1.5 \\
\hline 8 & AR-ULSD-2 & 5.6 & 6.6 & 1.0 & 44.0 & 42.0 & -2.0 & 15.7 & 16.6 & 0.9 & 27.7 & 29.1 & 1.4 \\
\hline 9 & AR-ULSD-4 & 4.4 & 5.6 & 1.2 & 43.5 & 43.3 & -0.2 & 25.9 & 24.1 & -1.8 & 35.9 & 32.4 & -3.5 \\
\hline 10 & AR-ULSD-5 & 5.4 & 6.0 & 0.6 & 41.1 & 40.7 & -0.4 & 25.2 & 27.2 & 2.0 & 37.1 & 37.5 & 0.4 \\
\hline 11 & AR-ULSD-6 & 5.6 & 5.9 & 0.3 & 41.9 & 40.8 & -1.1 & 23.3 & 25.9 & 2.6 & 35.8 & 36.6 & 0.8 \\
\hline 12 & AR-B10-1 & 4.0 & 4.8 & 0.8 & 43.2 & 46.0 & 2.8 & 18.8 & 17.0 & -1.8 & 27.9 & 27.6 & -0.3 \\
\hline 13 & AR-B10-2 & 3.7 & 4.5 & 0.8 & 40.7 & 41.3 & 0.6 & 18.2 & 17.7 & 0.5 & 27.4 & 28.6 & 1.2 \\
\hline 14 & AR-B10-4 & 4.0 & 5.1 & 1.1 & 40.9 & 43.4 & 2.5 & 18.8 & 16.2 & 2.6 & 29.1 & 29.3 & 0.2 \\
\hline 15 & AR-B20-1 & 3.0 & 3.6 & 0.6 & 37.5 & 38.1 & 0.6 & 25.2 & 21.3 & 3.9 & 33.0 & 29.3 & -3.7 \\
\hline 16 & AR-B20-2 & 3.7 & 3.7 & 0.0 & 37.9 & 39.6 & 1.7 & 15.4 & 12.8 & 2.6 & 23.0 & 21.3 & -1.7 \\
\hline 17 & AR-B20-5 & 3.5 & 3.7 & 0.2 & 36.9 & 38.7 & 1.8 & 10.0 & 10.5 & 0.5 & 18.4 & 19.2 & 0.8 \\
\hline 18 & AR-B20-6 & 3.6 & 4.5 & 0.9 & 39.9 & 43.2 & 3.3 & 14.1 & 13.1 & -1.0 & 23.1 & 23.3 & 0.2 \\
\hline \multicolumn{2}{|c|}{ RMS error } & & & 0.6 & & & 1.8 & & & 2.1 & & & 2.0 \\
\hline
\end{tabular}


Table 10 Fractional PM mass oxidized during passive oxidation and active regeneration phases of all experiments

\begin{tabular}{lllll}
\hline No & Expt. name & Temp ${ }^{\circ} \mathrm{C}$ & NO2-assisted (-) & Thermal (O2) (-) \\
\hline 1 & PO-B10-14 & 253 & 1.00 & 0.00 \\
2 & PO-B10-15 & 355 & 0.99 & 0.01 \\
3 & PO-B10-16 & 408 & 0.94 & 0.06 \\
4 & PO-B10-17 & 356 & 0.99 & 0.01 \\
5 & PO-B20-12 & 350 & 0.98 & 0.02 \\
6 & PO-B20-13 & 403 & 0.93 & 0.07 \\
7 & AR-ULSD-1 & 554 & 0.24 & 0.76 \\
8 & AR-ULSD-2 & 581 & 0.21 & 0.79 \\
9 & AR-ULSD-4 & 526 & 0.49 & 0.51 \\
10 & AR-ULSD-5 & 524 & 0.46 & 0.54 \\
11 & AR-ULSD-6 & 532 & 0.30 & 0.70 \\
12 & AR-B10-1 & 530 & 0.09 & 0.91 \\
13 & AR-B10-2 & 528 & 0.13 & 0.87 \\
14 & AR-B10-4 & 554 & 0.06 & 0.94 \\
15 & AR-B20-1 & 476 & 0.34 & 0.66 \\
16 & AR-B20-2 & 503 & 0.14 & 0.86 \\
17 & AR-B20-5 & 528 & 0.11 & 0.89 \\
18 & AR-B20-6 & 531 & 0.15 & 0.85 \\
\hline
\end{tabular}

Column marked "Temp." shows the average CPF temperature during passive oxidation and active regeneration phase, depending on the test case

\section{References}

1. Mahadevan, B.S., Johnson, J.H., and Shahbakti, M., Development of a catalyzed diesel particulate filter multi-zone model for simulation of axial and radial substrate temperature and particulate matter distribution, Journal of Emiss. Control Sci. Technol. doi:10.1007/ s40825-015-0015-X

2. Shiel, K.L., Naber, J., Johnson, J.H., and Hutton, C.R., Catalyzed particulate filter passive oxidation study with ULSD and biodiesel blended fuel, SAE Technical Paper No. 2012-01-0837,2012, doi: 10.4271/2012-01-0837

3. Pidgeon, J., Johnson, J.H., and Naber, J., An engine experimental investigation into the effects of biodiesel blends on particulate matter oxidation in a catalyzed particulate filter during active regeneration," SAE Technical Paper No. 2013-01-0521, SAE Congress (2013)

4. Shiel,K.L., Study of the effect of biodiesel fuel on passive oxidation in a catalyzed filter, Master's Thesis, Michigan Technological University, (2012)

5. Pidgeon, J., An experimental investigation into the effect of biodiesel blends on particulate matter oxidation in a catalyzed particulate filter during active regeneration," Master's Thesis, Michigan Technological University, (2013)

6. Foley, R., Johnson, J.H., Naber, J., and Rogoski, L., Experimental measurements of particulate matter distribution in a catalyzed particulate filter, Journal of Emiss. Control Sci. Technol. doi:10.1007/ s40825-014-0005-4

7. Foley, R., Experimental investigation into particulate matter distribution in catalyzed particulate filters using a 3D Terahertz wave scanner, MS Thesis, Michigan Technological University, (2013)
8. Konstandopoulos, A.G., Kostoglou, M., and Housiada, P., Spatial non-uniformities in diesel particulate trap regeneration, SAE Technical Paper No. 2001-01-0908, (2001)

9. Yi, Y., Simulating the soot loading in wall-flow DPF using a threedimensional macroscopic model, SAE Technical Paper No. 200601-0264, (2006)

10. Ranalli, M., Hossfeld, Christoph., Kaiser, Rolf., Schmidt, Stefan., and Elfinger, Gerhard., Soot loading distribution as a key factor for a reliable DPF system: an innovative development methodology, SAE Technical Paper No 2002-01-2158, (2002)

11. Kostoglou, M., Housiada, P., Konstandopoulos, A.G.: Multichannel simulation of regeneration in honeycomb monolithic diesel particulate filters. Chem. Eng. Sci. 58(14), 3273-3283 (2003). doi: 10.1016/S0009-2509(03)00178-7

12. Koltsakis, G., Haralampous, O., Depcik, C., Ragonoe, J.C.: Catalyzed diesel particulate filter modeling. Rev. Chem. Eng. 29(1), 1-61 (2013). doi:10.1515/revce-2012-008,2013

13. Premchand, K.C., Surenahalli, H., and Johnson, J., Particulate matter and nitrogen oxides kinetics based on engine experimental data for a catalyzed diesel particulate filter,SAE Technical Paper No. 2014-01-1553, (2014). doi:10.4271/2014-01-1553

14. Premchand, K.C., Development of a 1-D catalyzed diesel particulate filter for simulation of the performance and the oxidation of particulate matter and nitrogen oxides using passive oxidation and active regeneration engine experimental data, $\mathrm{PhD}$ Dissertation, Michigan Technological University, (2013)

15. Pinturaud, D., Charlet, A., Cailllol, C., Higelin, P., Girot, P., and Briot, A., Experimental study of DPF loading and incomplete regeneration, SAE Technical Paper No. 2007-24-0094, (2007)

16. Bensaid, S., Marchisio, D.L., Russo, N., Fino, D.: Experimental investigation of soot deposition in diesel particulate filters. Catl. Today 147(147S), 295S-300S (2009). doi:10.1016/j.cattod.2009. 07.039

17. Foley, R., Naber, J., Johnson, J., and Rogoski, L., Development of the methodology for quantifying the 3D PM distribution in catalyzed particulate filters using a 3D Terahertz wave scanner, SAE Technical Paper No. 2014-01-1573, (2014)

18. Delphi.com, Delphi DCM medium duty diesel engine controller series, http://delphi.com/shared/pdf/ppd/cv/pwrtm/ dcm-mediumduty-diesel-engine-controller-series.pdf, accessed on Sep, (2014)

19. Depcik, C., Assanis, D.: Graphical user interfaces in an engineering educational environment. Comput. Appl. Eng. Educ. 13(1), 48-59 (2005). doi:10.1002/cae.20029

20. Depcik, C., and Assanis, D., Simulating area conservation and the gas-wall interface for one-dimensional based diesel particulate filter models, Journal of Engineering for Gas Turbines and Power, November 2008, Vol.130/062807-1, (2008)

21. Kandylas, I.P., Haralampous, O.A., and Koltsakis, G.C., Disel soot oxidation with $\mathrm{NO} 2$ : engine experiments and simulations, industrial engineering and chemistry research, Volume 41, 5372-5384, No.22, (2002)

22. Haralampous, O.C., Koltsakis, G.C., and Samaras, Z.C., Partial regenerations in diesel particulate filters, SAE Technical paper No. 2003-01-1881, (2003)

23. Sappok, A., Wang, Y., Wang, R., Kamp, C., Theoretical and experimental analysis of ash accumulation and mobility in ceramic exhaust particulate filters and potential for improved ash management, SAE Int.J.Fuel Lubr. Volume 7, Issue 2, June (2014), doi:10.4271/ 20444-01-1941

24. Boehman, A.L., Song. J., and Alam, M., Impact of biodiesel blending on diesel soot and the regeneration of particulate filters, Journal of Energy and Fuels, Vol. 19, page. 1857-1864, (2005)

25. Vertin, K., He, S., and Heibel, A., Impacts of B20 biodiesel on cordierite diesel particulate fiter performance, SAE Tech. Paper No.2009-01-2736, (2009) 